\title{
Online Fault-Tolerant Onboard Aeroengine Model Tuning Structure
}

\author{
Shuiting Ding, ${ }^{1}$ Ye Yuan, ${ }^{1}$ Naiyu Xue, ${ }^{2}$ and Xiaofeng Liu ${ }^{2}$ \\ ${ }^{1}$ School of Energy and Power Engineering, Beijing University of Aeronautics and Astronautics, Beijing, China \\ ${ }^{2}$ School of Transportation Science and Engineering, Beijing University of Aeronautics and Astronautics, Beijing, China \\ Correspondence should be addressed to Xiaofeng Liu; liuxf@buaa.edu.cn
}

Received 9 July 2016; Revised 7 October 2016; Accepted 19 October 2016

Academic Editor: Kenneth M. Sobel

Copyright (c) 2016 Shuiting Ding et al. This is an open access article distributed under the Creative Commons Attribution License, which permits unrestricted use, distribution, and reproduction in any medium, provided the original work is properly cited.

\begin{abstract}
Online onboard aeroengine models (OBEMs) have been widely used in health management, fault diagnostics, and fault-tolerant control. A mismatch between the OBEM and the actual engine may be caused by a variety of factors such as health degradation or sensor fault and may influence the effectiveness of the systems mentioned above. However, mismatch caused by unpredictable sensor fault is hardly distinguished from that caused by health degradation through the tuning process. A fault-tolerant OBEM tuning structure is provided to perform the online tuning function when health degradation and sensor fault coexist. This system includes three parts that include improved fault diagnostics and isolation (IFDI), a fault-tolerant OBEM tuning system (FTOTS), and a channel switching module. IFDI is used to distinguish the cause of mismatch and provide fault information, a FTOTS is used to complete an online tuning process based on information obtained from the IFDI, and the channel switching module is used to switch the working process from the IFDI to the FTOTS. Several simulation results show that this system is able to distinguish the causes of mismatch and complete online tuning in the case of sensor faults.
\end{abstract}

\section{Introduction}

Aeroengines are operated in harsh environments with high temperatures, pressures, and speeds, and the deterioration of components is unavoidable. The performance of components, sensors, and actuators slowly degrades during regular operations [1]. During actual flight, highly condensed sand, or salt can accelerate fan or compressor degradation, and tropical heat can accelerate turbine degradation [2]. The damage caused by foreign objects primarily affects the fan and front part of the engine, with the extent of the damage determined by the geometry, angle of impact, hardness, and relative speed, amongst other factors, of the object [3]. Volcanic ash may severely affect the hot section of the engine while producing no visible damage to the cooler portions in the front of the engine [3], and ash ingested by the engine can lead to an immediate degradation of engine performance [4].

Unpredictable sensor fault may occur during flight. The Kalman filter has proved to be a useful tool in sensor fault detection, and in recent years, different diagnostics systems based on the Kalman filter have been developed to detect sensor faults [5-12]. The fault diagnostics systems are designed based on the nondegrade condition of the engine, which has become a reference health baseline for diagnostics processes, and any observed deviations from the measured outputs of the reference baseline outputs may be indicative of a fault. However, as previously referenced, health degradation causes the outputs of the actual engine to deviate from the reference health baseline. When the deviation exceeds a certain level, it becomes difficult to distinguish the fault from the mismatch that caused the health degradation, merely by observing the measured outputs.

In various studies [7-9], fault detection and isolation (FDI) based on the Kalman filter have been proven capable of identifying faulty sensor location when health degradation and sensor fault coexist; however, this diagnostics system may lose its effectiveness when the health degradation exceeds a certain level. Therefore, the diagnostics system based on the Kalman filter must be improved to accommodate severely degraded engines.

Onboard aeroengine models (OBEMs) have been commonly used in recent years to provide information for fault 
diagnostics and engine control. As advanced control systems, health monitoring and diagnosis systems with OBEM were developed to improve the performance and safety of aeroengines. The NASA Glenn Research Center (GRC) proposed an intelligent engine control system that includes active control, health management, and fault-tolerant control technologies $[13,14]$. The latest model-based control system uses OBEM to calculate unmeasured outputs such as aeroengine thrust, compressor stall, and surge [15]. In 2006, the GRC introduced OBEM into the structure of the linear Kalman filter to establish the hybrid Kalman filter (HKF) [16, 17]. In the following years, the HKF was used for engine performance estimation and sensor fault detection $[18,19]$. Pourbabaee et al. introduced the HKF into an FDI to achieve the functions of sensor fault detection, isolation, and identification [20, 21].

Recently, a real-time self-tuning OBEM has been combined with a health management structure [22]. Simon et al. presented a real-time self-tuning model used for engine performance monitoring and fault diagnostics [22-24]. This model is a hybrid model including an OBEM and neural networks. Furthermore, Volponi et al. presented an online tuning engine model updated with a Kalman filter [25, 26]. This kind of an OBEM is able to minimize the mismatch between an OBEM and the actual engine and maintain the effectiveness of the fault diagnostics system. However, during the tuning process, the influence of a faulty signal is not considered, so a tuning system with a fault-tolerant function must be developed because an online tuning system may encounter coexisting health degradation and sensor fault.

The following contents of this paper include three sections. Section 2 presents a general description of faulttolerant tuning structures and the development of different parts including the improved fault diagnostics and isolation (IFDI), fault-tolerant OBEM tuning system (FTOTS), and the channel switching module. Section 3 includes the simulation results, which were used to prove the effectiveness of the system. The last section contains the conclusions of this work.

\section{Fault-Tolerant Online Tuning Structure}

Health degradation and sensor fault are both capable of causing a mismatch between the OBEM and the actual engine. If health degradation and sensor fault coexist, an analysis of the mismatch and the corresponding method to minimize the mismatch must be provided. During the traditional online tuning process, the information used for the tuning process contains measurement noise, sensor bias, and any attendant modeling error; however, the effect of the senor fault is not typically considered [26]. If the mismatch is caused only by sensor fault, the tuning process should not be initiated because this kind of mismatch cannot be solved by updating health information. During the online OBEM tuning process, the influence of a faulty sensor should be considered because the mismatch caused by the faulty signal will also be considered during the tuning process. If the online tuning system is able to remove the corresponding faulty signal, the tuning results will be accurate and the mismatch between the OBEM and actual engine will be minimized.

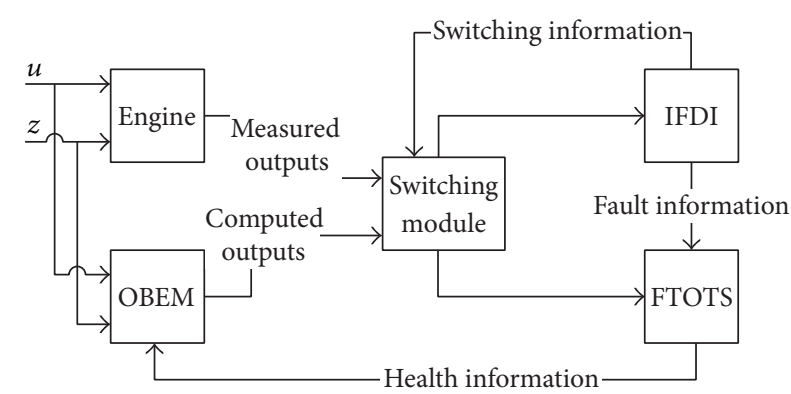

FIGURE 1: A general fault-tolerant OBEM tuning structure.

The FTOTS is used to analyze the mismatch cause and to minimize the mismatch caused by health degradation. The functions of this system include sensor fault diagnostics and fault-tolerant online OBEM tuning. There are three main components of this system including the IFDI, the FTOTS, and the channel switching module. The IFDI is used in the estimation process to locate the faulty sensor, and the FTOTS is used in the tuning process to minimize the mismatch. The two systems work on different channels and are switch triggered by the signal. The general structure is shown in Figure 1.

The IFDI is developed based on FDI. The IFDI has two tasks, sensor fault diagnostics and online tuning operation decision. The IFDI is used to locate the faulty sensor and make the channel switching decision. Compared with conventional FDI, IFDI has the extra function of providing switching information to the channel switching module.

The FTOTS combines the OBEM tuning system (OTS) with fault-tolerant function. FTOTS is used to remove faulty input signals based on the fault information of the IFDI and minimize the mismatch caused by health degradation. In this system, the number of measured outputs is greater than that of health parameters, so the absence of single signal will not affect the estimation of the Kalman filter.

The channel switching module is used to perform the function of channel switching between the estimation processes and tuning process. During the estimation process of the IFDI, the health information provided to the OBEM retains its original values $h_{\text {ref }}[14]$; however, during the tuning process the health parameters are tuned by the FTOTS. Different working conditions mean that the IFDI and the FTOTS will not work in parallel; otherwise, there interruption occurs between the two systems. The channel switching module is able to resolve the conflict between the IFDI and the FTOTS. The channel switching process between the IFDI and the FTOTS of the system is shown in Figure 2.

2.1. IFDI Structure. In this paper, the IFDI and the FTOTS are both established based on a nonlinear component-level engine model [27]. The model is a two-spool high-bypass turbofan engine. Linearization computation is completed based on the two-step perturbation method [27]. The linear model in state-space form is

$$
\begin{aligned}
& \Delta \dot{x}(t)=A \Delta x(t)+B \Delta u(t)+L \Delta h(t)+G \Delta z(t), \\
& \Delta y(t)=C \Delta x(t)+D \Delta u(t)+M \Delta h(t)+H \Delta z(t),
\end{aligned}
$$




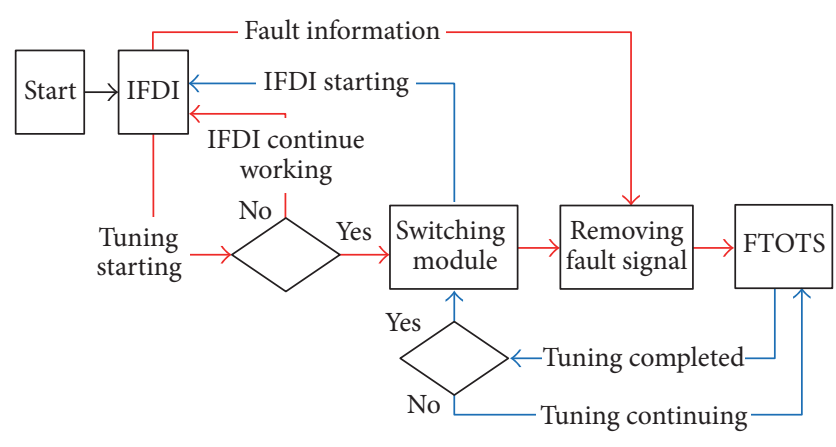

FIGURE 2: The channel switching process of a fault-tolerant OBEM tuning structure.

where $x$ represents the state variables of the engine, such as $x=\left[\begin{array}{ll}N_{H} & N_{L}\end{array}\right]^{T}, u$ represents the control input of the engine such as the fuel input, and $h$ represents the health parameter. The health parameters are the efficiency and flow capacity of the engine compressors and turbines. As they deviate from the nominal baseline, the performance delivered by each component degrades [2]. $z$ presents the environmental inputs such as altitude and Mach number, $y$ represents the measured outputs of the engine, and $A, B, C, D, L, M, G$, $H$ are the corresponding matrices of the model. The engine health parameters are listed as follows:

Fan efficiency $\left(E_{\text {fan }}\right)$ and fan flow capacity $\left(F_{\text {fan }}\right)$.

LPC efficiency $\left(E_{\text {LPC }}\right)$ and LPC flow capacity $\left(F_{\text {LPC }}\right)$. $\mathrm{HPC}$ efficiency $\left(E_{\mathrm{HPC}}\right)$ and HPC flow capacity $\left(F_{\mathrm{HPC}}\right)$. $\mathrm{HPT}$ efficiency $\left(E_{\mathrm{HPT}}\right)$ and HPT flow capacity $\left(F_{\mathrm{HPT}}\right)$. LPT efficiency $\left(E_{\mathrm{LPT}}\right)$ and LPT flow capacity $\left(F_{\mathrm{LPT}}\right)$.

And the engine measured outputs are listed as follows:

High pressure rotor speed $\left(N_{H}\right)$ and low pressure rotor speed $\left(N_{L}\right)$.

Outlet pressure of fan $\left(\mathrm{OP}_{\mathrm{fan}}\right)$ and outlet temperature of fan $\left(\mathrm{OT}_{\mathrm{fan}}\right)$.

Outlet pressure of LPC $\left(\mathrm{OP}_{\mathrm{LPC}}\right)$ and outlet temperature of LPC $\left(\mathrm{OT}_{\mathrm{LPC}}\right)$.

Outlet pressure of $\mathrm{HPC}\left(\mathrm{OP}_{\mathrm{HPC}}\right)$ and outlet temperature of $\mathrm{HPC}\left(\mathrm{OT}_{\mathrm{HPC}}\right)$.

Outlet pressure of HPT $\left(\mathrm{OP}_{\mathrm{HPT}}\right)$ and outlet temperature of HPT $\left(\mathrm{OT}_{\mathrm{HPT}}\right)$.

Engine exhaust pressure (EGP) and engine exhaust temperature (EGT).

$\mathrm{HKF}$ is a hybrid structure consisting of a Kalman filter and OBEM, and the OBEM receives offline $h_{\text {ref }}$ as reference to minimize the deviation of the measured outputs between the OBEM and the actual engine. The establishment of the HKF is completed based on the literature $[16,17]$ with a form of

$$
\begin{aligned}
\Delta \dot{x}_{\mathrm{kal}} & =A_{\mathrm{kal}}\left(x_{\mathrm{kal}}-x_{\mathrm{OBEM}}\right)+K_{\mathrm{kal}}(y-\widehat{y}), \\
\widehat{y} & =C_{\mathrm{kal}}\left(x_{\mathrm{kal}}-x_{\mathrm{OBEM}}\right)+y_{\mathrm{OBEM}},
\end{aligned}
$$

where $x_{\mathrm{kal}}=\left[\begin{array}{l}x \\ h\end{array}\right], A_{\mathrm{kal}}=\left[\begin{array}{cc}A & L \\ 0 & 0\end{array}\right], B_{\mathrm{kal}}=\left[\begin{array}{l}B \\ 0\end{array}\right]$, and $C_{\mathrm{kal}}=$ $\left[\begin{array}{ll}C & M\end{array}\right] . K_{\mathrm{kal}}$ is the gain matrix of the HKF, $y$ is the measured output, and $\hat{y}$ is the estimated measured output of HKF. The gain matrix $K_{\mathrm{kal}}$ is calculated based on the literature [28].

The IFDI consists of a bank of HKFs. For sensor fault detection, $n$ HKFs are designed where $n$ is the number of sensors. Each HKF estimates the corresponding state variables of the engine based on a unique set of $n-1$ sensors. The sensor that is not used by a particular HKF is the hypothetical faulty one monitored by that HKF.

The functions of the IFDI are performed based on a weighted sum of squared residuals (WSSR) [16]. Each HKF in the IFDI computes the corresponding WSSR. Compared with conventional FDI, there are two kinds of WSSR in IFDI; one is WSSR $_{\mathrm{HKF}}$, which represents the deviation of outputs between $\mathrm{HKF}$ and the actual engine, and the other is WSSR $\mathrm{OBEM}_{\text {, }}$, which represents the deviation of outputs between the OBEM and the actual engine. The function of faulty sensor location is achieved based on WSSR $\mathrm{HKF}_{\mathrm{F}}$, and the function of online tuning decision is achieved based on WSSR $\mathrm{OBEM}_{\text {. The form }}$ of WSSR corresponding to the $i$ th HKF is

$$
\begin{aligned}
\operatorname{WSSR}_{\mathrm{HKF}}^{i} & =W_{r}^{i}\left(e_{\mathrm{HKF}}^{i}\right)^{T} e_{\mathrm{HKF}}^{i}, \\
\mathrm{WSSR}_{\mathrm{OBEM}}^{i} & =W_{r}^{i}\left(e_{\mathrm{OBEM}}^{i}\right)^{T} e_{\mathrm{OBEM}}^{i},
\end{aligned}
$$

where $e_{\mathrm{HKF}}^{i}=y^{i}-\hat{y}^{i}, e_{\mathrm{OBEM}}^{i}=y^{i}-y_{\mathrm{OBEM}}^{i}$, and $y^{i}$ are the outputs from $n-1$ sensors that the $i$ th Kalman filter uses, $y_{\mathrm{OBEM}}^{i}$ are the corresponding outputs from the OBEM used as the baseline outputs of the $i$ th Kalman filter, and $\hat{y}^{i}$ are the corresponding estimated outputs of the $i$ th Kalman filter. $W_{r}^{i}$ represents the corresponding weighting factor of the $i$ th Kalman filter, $W_{r}^{i}=\left(y_{\text {OBEM }}^{i}\right)^{-2}$. The computation of WSSR is shown in Figure 3.

The sensor fault detection and online tuning decision logic is designed as shown in Figure 4. If there is no sensor fault, all WSSR $\mathrm{HKF}_{\mathrm{H}} \mathrm{s}$ are lower than the corresponding threshold, and the sensor fault diagnostics results of the IFDI are 0 . If the $i$ th sensor is faulty, all HKFs will use corrupted information except for the $i$ th one. It is able to accommodate the faulty sensor and is thus able to estimate health information more accurately because the estimated results are not affected by the faulty signal. The WSSR ${ }_{\mathrm{HKF}}^{i}$ corresponding to the faulty sensor should be lower than the corresponding threshold and the remaining $n-1 \mathrm{WSSR}_{\mathrm{HKF}} \mathrm{s}$ are higher than thresholds; therefore, the faulty sensor can be located. Meanwhile, the WSSR $_{\text {OBEM }}^{i}$ of the $i$ th HKF is used to show the mismatch between the OBEM and the actual engine because it is not affected by the faulty signal. When the value of the $\mathrm{WSSR}_{\mathrm{OBEM}}^{i}$ exceeds the threshold $\eta_{i}$, the online tuning system should be initiated; this step comprises the additional function provided by the IFDI.

The threshold values $\lambda_{i}$ and $\eta_{i}$ are determined using diagnostics logic. Setting the threshold $\lambda_{i}$ to a low value increases the chance of detecting faults but also increases the chance of generating false alarms and vice versa. The threshold $\eta_{i}$ is set to ensure that the online tuning process 


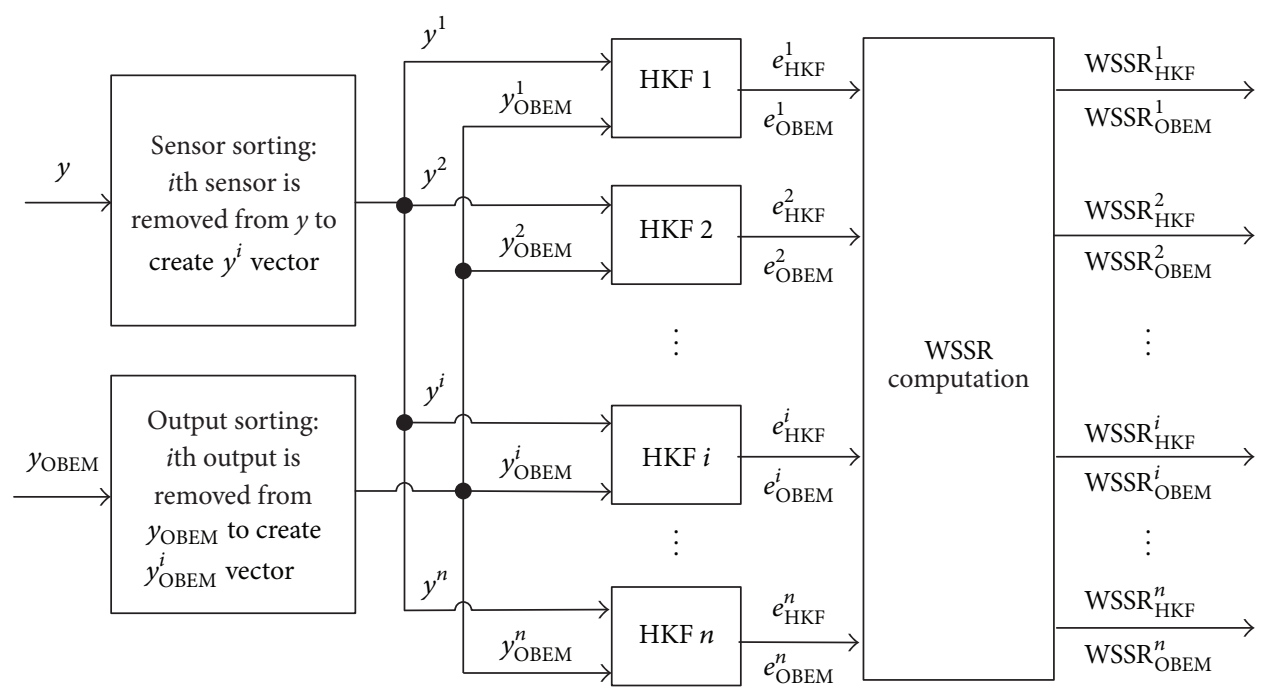

FIgURE 3: Computation of WSSR.

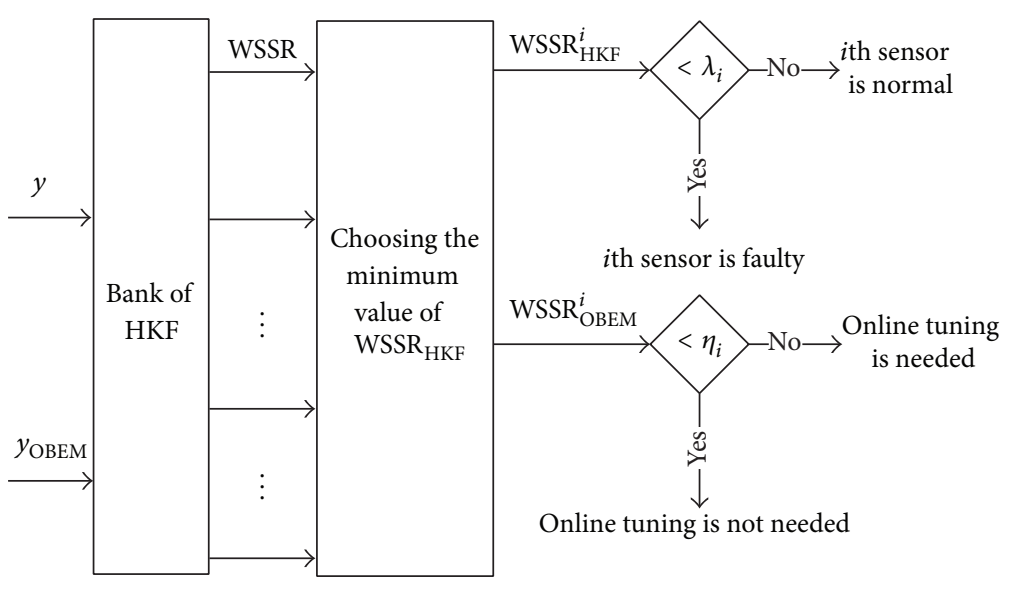

FIgURE 4: Sensor fault detection and online tuning decision logic.

is not falsely triggered by process and measurement noise interference. It would be reasonable to use different threshold values at different power settings to achieve effective fault detection performance [16]. The sensors have measurement deviations, and mismatch caused by sensor deviation is unavoidable, so the standard deviations of the sensors should be considered in the selection of thresholds in order to avoid false alarms. In this paper, the WSSRs were computed with dimensionless treatment, and thus the thresholds of different HKFs should be set at the same order of magnitude at the corresponding power setting.

2.2. Development of FTOTS. FTOTS refers to an improved OTS with a fault-tolerant function. An OTS is developed using an HKF to perform the function of online OBEM tuning, and it consists of a closed-loop structure consisting of a Kalman filter and an OBEM. In an OTS, a Kalman filer is used as the "controller" to produce the outputs from the OBEM used to track the outputs of the actual engine. The OBEM receives health information from the Kalman filter to compute tuned measured outputs. The OTS is a type of nonlinear estimator because the estimation of the measured outputs is completed by a nonlinear OBEM. The OTS takes advantage of the high degree of matching between the OBEM and the actual engine to improve the accuracy of estimation and to reduce the estimation error caused by discrepancies between the state-space formulation of the filter and the actual engine. The general structure of an OTS is shown in Figure 5.

An OBEM in an OTS is represented by

$$
\begin{aligned}
& \dot{x}_{\mathrm{OBEM}}=f\left(x_{\mathrm{OBEM}}, u, \widehat{h}, z\right), \\
& y_{\mathrm{OBEM}}=g\left(x_{\mathrm{OBEM}}, u, \widehat{h}, z\right),
\end{aligned}
$$




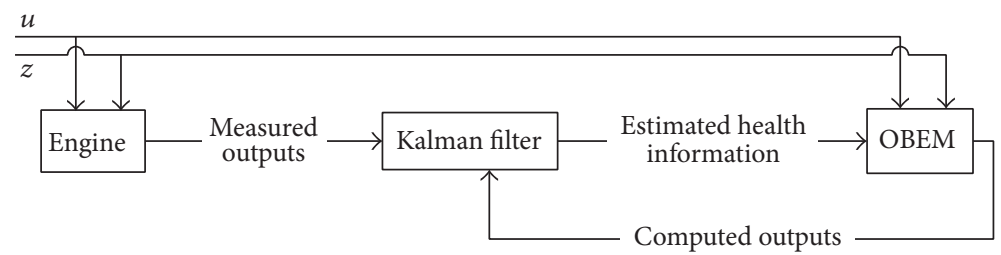

FIGURE 5: General structure of an OTS.

where the OBEM receives health information from the Kalman filter in real-time, and the outputs of the Kalman filter are estimated health information $\widehat{h}=h_{\text {ref }}+\Delta \widehat{h}$. The structure of the Kalman filter is simplified because it does not need to compute measured outputs. The structure of the Kalman filter is converted into

$$
\begin{aligned}
\Delta \dot{x}_{\mathrm{kal}} & =A_{\mathrm{kal}} \Delta x_{\mathrm{kal}}+K_{\mathrm{kal}}\left(y-y_{\mathrm{OBEM}}\right), \\
\Delta \widehat{h} & =C_{\mathrm{kal}} \Delta x_{\mathrm{kal}},
\end{aligned}
$$

where $C_{\mathrm{kal}}=\left[\begin{array}{ll}0 & 0 \\ 0 & \mathrm{IM}\end{array}\right], K_{\mathrm{kal}}=\left[\begin{array}{l}k_{1} \\ k_{2}\end{array}\right], k_{1}$ is related to the rotor speed, $k_{2}$ is related to the health parameter, and IM is the identity matrix.

$x_{\mathrm{kal}}$ of the filter consists of two parts, $x_{\mathrm{kal}}=\left[\begin{array}{c}x \\ h\end{array}\right]$, where $x$ represents the rotor speed and $h$ represents the health parameter. According to $A_{\mathrm{kal}}=\left[\begin{array}{cc}A & L \\ 0 & 0\end{array}\right]$, the variation in $x$ will not affect the variation in $h$, and there is no coupling relationship between the two parts. As variation in the rotor speed is not computed in an OTS, the elements of matrices associated with rotor speed can be removed from the Kalman filter such that $x_{\mathrm{kal}}^{\prime}=h, A_{\mathrm{kal}}^{\prime}=\left[\begin{array}{ll}0 & 0\end{array}\right]$, and $K_{\mathrm{kal}}^{\prime}=k_{2}$.

The simplified structure of the Kalman filter in an OTS is shown in (6). $C_{\text {kal }}$ becomes IM, $A_{\text {kal }}^{\prime}$ and $K_{\mathrm{kal}}^{\prime}$ are part of $A_{\mathrm{kal}}$ and $K_{\mathrm{kal}}$, and the elements of $A_{\mathrm{kal}}$ and $K_{\mathrm{kal}}$ related to rotor speed are removed to establish $A_{\mathrm{kal}}^{\prime a}$ and $K_{\mathrm{kal}}^{\prime}$.

$$
\begin{aligned}
\Delta \dot{x}_{\mathrm{kal}}^{\prime} & =A_{\mathrm{kal}}^{\prime} \Delta x_{\mathrm{kal}}^{\prime}+K_{\mathrm{kal}}^{\prime}\left(y-y_{\mathrm{OBEM}}\right), \\
\Delta \widehat{h} & =\mathrm{IM} \Delta x_{\mathrm{kal}}^{\prime} .
\end{aligned}
$$

$A_{\text {kal }}^{\prime}$ becomes a zero matrix because the values of the elements that are related to health parameters equal 0 ; thus, the structure of the Kalman filter becomes

$$
\begin{aligned}
\Delta \dot{x}_{\mathrm{kal}}^{\prime} & =K_{\mathrm{kal}}^{\prime}\left(y-y_{\mathrm{OBEM}}\right), \\
\Delta \widehat{h} & =\mathrm{IM} \Delta x_{\mathrm{kal}}^{\prime} .
\end{aligned}
$$

The structure of the OTS can be described by

$$
\begin{aligned}
\Delta \dot{x}_{\mathrm{kal}}^{\prime} & =K_{\mathrm{kal}}^{\prime}(y-\hat{y}), \\
\widehat{y} & =y_{\mathrm{OBEM}} .
\end{aligned}
$$

The OTS is similar to a closed-loop control system. To achieve a quick and smooth tuning process and maintain stability of system, gain matrix $K_{\mathrm{kal}}^{\prime}$ is computed based on the linear quadratic regulator theory $[29,30]$. The linear quadratic computations are completed based on the complete form of the Kalman filter in the OTS because the state variables of the Kalman filter in the OTS do not contain rotor speeds and the estimated measured outputs are removed. Furthermore, $K_{\mathrm{kal}}^{\prime}$ is extracted from $K_{\mathrm{kal}}$, and the Kalman filter in the OTS is transformed into the complete form

$$
\begin{aligned}
\Delta \dot{x}_{\mathrm{kal}} & =A_{\mathrm{kal}} \Delta x_{\mathrm{kal}}+K_{\mathrm{kal}}(-\Delta \hat{y}), \\
\Delta \hat{y} & =C_{\mathrm{kal}} \Delta x_{\mathrm{kal}},
\end{aligned}
$$

where $K_{\mathrm{kal}} \Delta \hat{y}=C_{\mathrm{kal}}\left(K_{\mathrm{kal}} \Delta x_{\mathrm{kal}}\right)$ and input parameter $\Delta u_{\mathrm{lq}}=$ $-K_{\mathrm{kal}} \Delta x_{\mathrm{kal}}$.

The quadratic performance index is

$$
J_{\mathrm{kal}}=\int_{0}^{\infty}\left(\Delta x_{\mathrm{kal}}{ }^{T} \mathrm{QM} \Delta x_{\mathrm{kal}}+\Delta u_{\mathrm{lq}}{ }^{T} \mathrm{RM} \Delta u_{\mathrm{lq}}\right) d t,
$$

where QM and RM are state deviation weighting and control deviation weighting matrices, $\mathrm{QM}=\mathrm{QM}^{T} \geq 0, \mathrm{RM}=$ $\mathrm{RM}^{T} \geq 0$, the Riccati equation is introduced to compute the optimal gain matrix, and the positive definite and symmetric matrix $P$ can be computed by

$$
\begin{gathered}
A_{\text {kal }} \otimes P+P \otimes A_{\text {kal }}^{T}-P \otimes C_{\text {kal }}^{T} \otimes \mathrm{RM}^{-1} \otimes C_{\text {kal }} \otimes P \\
+\mathrm{QM}=0 .
\end{gathered}
$$

$\Delta u_{\text {lq }}$ is

$$
\Delta u_{\mathrm{lq}}=-\mathrm{RM}^{-1} C_{\mathrm{kal}}^{T} P \Delta x_{\mathrm{kal}} .
$$

$K_{\text {kal }}$ is

$$
K_{\text {kal }}=\mathrm{RM}^{-1} C_{\text {kal }}{ }^{T} P .
$$

The elements related to speed rotors in $K_{\text {kal }}$ are removed to compute $K_{\mathrm{kal}}^{\prime}$.

To adapt to different situations, a linear parametervarying (LPV) structure is introduced into the Kalman filter in the OTS. The LPV structure of the OTS is established based on the literature [31]. The nonlinear engine is viewed as a collection of linear models corresponding to the measured outputs and environmental inputs [32]. The LPV model is 


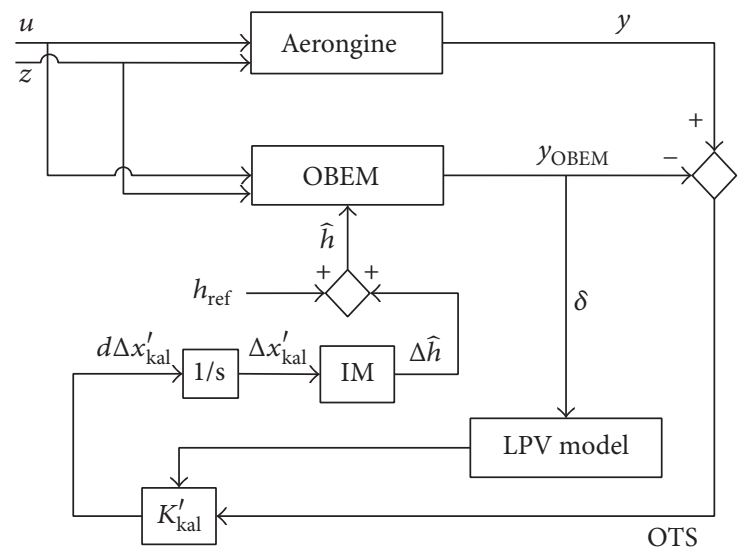

FIGURE 6: Structure of the OTS.

established based on a family of linear models at multiple operation points. The functions between the elements of the linear model and the scheduling parameters are established, and the scheduling parameters are chosen from the measured outputs of the OBEM and environmental inputs. In an LPV structure, the elements of the matrices will be associated in parallel with the scheduling parameters. In this paper $N_{H}$ is chosen as the scheduling parameter $\delta$ in the LPV structure of the OTS. There are functions between the family of $N_{H}$ and corresponding elements of matrices in the OTS at different steady-state points. The elements of the OTS will be tuned in parallel with the variation in $N_{H}$. Equation (14) and Figure 6 show the structure.

$$
\begin{aligned}
\Delta \dot{x}_{\mathrm{kal}}^{\prime} & =K_{\mathrm{kal}}^{\prime}(\delta)(y-\hat{y}), \\
\hat{y} & =y_{\mathrm{OBEM}} .
\end{aligned}
$$

The FTOTS is established based on the OTS. The FTOTS has an input selection function (ISF) to remove faulty signal. The form of the FTOTS is

$$
\begin{aligned}
\Delta \dot{x}_{\mathrm{kal}}^{\prime} & =K_{\mathrm{kal}}^{\prime}(\delta) \operatorname{ISF}\left(\mathrm{FS}_{\text {sensor }}\right)(y-\hat{y}), \\
\hat{y} & =y_{\text {OBEM }} .
\end{aligned}
$$

When there is no sensor fault information, $\mathrm{FS}_{\text {sensor }}$ equals 0 , and ISF is the identity matrix. Once fault information is provided, the corresponding element of ISF becomes zero, and the faulty signal will not affect the tuning process of the FTOTS.

When the tuning process is completed, the channel switching module should switch to the estimation process, so that the FTOTS provides switching information to the switching module. The end points of the tuning include two parts: one is the variation rate of the estimated health parameters and the other is the $\operatorname{WSSR}_{\text {OBEM }}^{i}$ corresponding to the faulty sensor. When the variation rate of the estimated health parameter approaches zero and the WSSR OBEM $_{\text {of the }}$

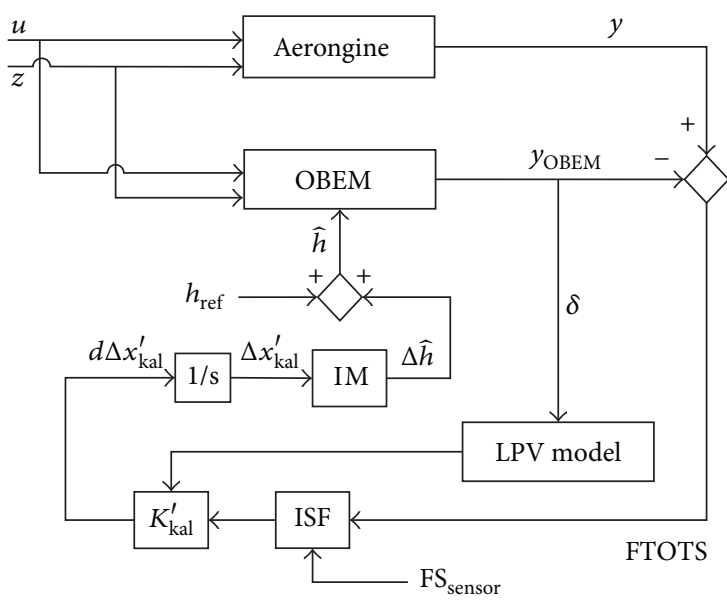

FIgUre 7: Structure of the FTOTS.

faulty sensor is lower than the corresponding threshold $\eta_{i}$, the tuning process is completed. The structure of the FTOTS is shown in Figure 7.

Note that there are multiple operation points in the LPV structure of the OTS. Considering that the length of paper is limited, an operation point of the engine is chosen from the collection of operation points in the LPV structure to show the computation process of gain matrix $K_{\mathrm{kal}}^{\prime}$ in the OTS.

The operation point of the engine model is used in this paper with the data $x=\left[\begin{array}{ll}N_{H} & N_{L}\end{array}\right]^{T}, y=$ $\left[\begin{array}{lllllll}N_{H} & N_{L} & \mathrm{OT}_{\mathrm{fan}} & \mathrm{OP}_{\mathrm{fan}} & \mathrm{OT}_{\mathrm{HPC}} & \mathrm{OP}_{\mathrm{HPC}}\end{array}\right]^{T}$, and $h=$ $\left[\begin{array}{llll}E_{\mathrm{fan}} & E_{\mathrm{HPC}} & E_{\mathrm{HPT}} & E_{\mathrm{LPT}}\end{array}\right]^{T}$.

To show the variation in health parameters directly, the degradation coefficients (DCs) of the health parameters are used to represent the ratio of the degraded health parameter to the nominal health parameter. In the model, the DCs of the health parameters are defined as

$$
\begin{aligned}
\mathrm{DC}_{E_{\mathrm{fan}}} & =\frac{E_{\text {fan,deg radation }}}{E_{\text {fan, noimal }}}, \\
\mathrm{DC}_{E_{\mathrm{HPC}}} & =\frac{E_{\mathrm{HPC}, \text { deg radation }}}{E_{\mathrm{HPC}, \text { noimal }}}, \\
\mathrm{DC}_{E_{\mathrm{HPT}}} & =\frac{E_{\mathrm{HPT}, \text { deg radation }}}{E_{\mathrm{HPT}, \text { noimal }}}, \\
\mathrm{DC}_{E_{\mathrm{LPT}}} & =\frac{E_{\mathrm{LPT}, \text { deg radation }}}{E_{\mathrm{LPT}, \text { noimal }}} .
\end{aligned}
$$

The state variables of the Kalman filter in the FTOTS are $x_{\mathrm{kal}}^{\prime}=\left[\begin{array}{llll}\mathrm{DC}_{E_{\mathrm{fan}}} & \mathrm{DC}_{E_{\mathrm{HPC}}} & \mathrm{DC}_{E_{\mathrm{HPT}}} & \mathrm{DC}_{E_{\mathrm{LPT}}}\end{array}\right]^{T}$.

The operation point of the engine is $x=\left[\begin{array}{ll}6920 & 3682\end{array}\right]^{T}$, and the corresponding matrices are 


$$
\begin{aligned}
& A_{\mathrm{kal}}=\left[\begin{array}{cccccc}
-5.9555 e-1 & -3.2675 e-1 & 7.2190 e 1 & -6.6833 e 3 & -8.4614 e 3 & -1.6744 e 1 \\
3.4872 e-1 & -1.0403 & -2.0246 e 3 & 3.5306 e 2 & 3.5548 e 2 & -2.1750 e 3 \\
0 & 0 & 0 & 0 & 0 & 0 \\
0 & 0 & 0 & 0 & 0 & 0 \\
0 & 0 & 0 & 0 & 0 & 0 \\
0 & 0 & 0 & 0 & 0 & 0
\end{array}\right] \text {, } \\
& C_{\mathrm{kal}}=\left[\begin{array}{cccccc}
1 & 0 & 0 & 0 & 0 & 0 \\
0 & 1 & 0 & 0 & 0 & 0 \\
-1.9975 e-4 & 7.9158 e-3 & 1.7281 e 1 & 1.0851 e-1 & 1.1191 e-1 & -9.9153 e-3 \\
-2.7605 e-1 & 9.6362 & 5.1711 e 2 & 1.5631 e 2 & 1.6452 e 2 & -5.7998 \\
3.3112 e-2 & 2.2213 e-2 & 2.4988 e 1 & 2.9336 e 2 & 2.8507 e-1 & 4.9636 e-4 \\
1.2545 e 2 & 1.4453 e 2 & -3.8159 e 4 & 5.2069 e 4 & -8.1884 e 4 & -5.4656 e 2
\end{array}\right] .
\end{aligned}
$$

The values of $\mathrm{QM}$ and $\mathrm{RM}$ are set to $\mathrm{QM}=1 e-2 \otimes \mathrm{IM}_{6 \times 6}$ and $\mathrm{RM}=1 e 5 \otimes \mathrm{IM}_{6 \times 6}$, and according to (11), the value of matrix $P$ is

$$
P=\left[\begin{array}{cccccc}
2.7687 e 4 & -3.7238 e 3 & 1.6066 e 1 & -2.2022 e 1 & 1.4089 e 1 & -7.9049 e-1 \\
-3.7238 e 3 & 3.6662 e 3 & -1.0028 e 1 & -3.2553 & 3.3513 & 4.6983 \\
1.6606 e 1 & -1.0028 e-4 & 2.6593 e-5 & -1.7107 e-4 & 1.7806 e-4 & -4.9549 e-5 \\
-22.0222 & -3.25529 & 4.6174 e-2 & 4.4899 e-2 & -3.1945 e-2 & -4.3312 e-2 \\
1.4089 e 1 & 3.3513 & -3.6636 e-2 & -3.1945 e-2 & 2.4349 e-2 & 3.2363 e-2 \\
-7.0949 & 4.6983 & -1.3572 e-1 & -4.3313 e-2 & 3.2363 e-2 & 1.2449 e-1
\end{array}\right] .
$$

Furthermore, the computation result of gain matrix $K_{\mathrm{kal}}$ based on (13) is

$$
K_{\mathrm{kal}}=\left[\begin{array}{cccccc}
2.7688 e-1 & -3.7238 e-2 & 2.4189 e-3 & -3.6301 e-1 & -5.2211 e-2 & 2.5885 e-1 \\
-3.7238 e-2 & -3.6662 e-2 & 1.4355 e-3 & 3.1186 e 01 & -1.2464 e-2 & -1.1413 e-2 \\
1.6606 e-4 & -1.0028 e-4 & 2.6593 e-5 & -1.7107 e-4 & 1.7806 e-4 & -4.9549 e-5 \\
-2.2022 e-4 & -3.2553 e-5 & 7.7828 e-6 & 6.0134 e-6 & 1.3515 e-4 & -1.7911 e-4 \\
1.4089 e-4 & 3.3513 e-5 & -6.1045 e-6 & 8.2847 e-5 & -9.7390 e-5 & -2.5028 e-4 \\
-7.0949 e-5 & 4.6983 e-5 & -2.3091 e-5 & -2.5119 e-4 & -1.6219 e-4 & -5.3121 e-5
\end{array}\right]
$$

and the corresponding gain matrix $K_{\mathrm{kal}}^{\prime}$ in OTS is

$$
K_{\mathrm{kal}}^{\prime}=\left[\begin{array}{cccccc}
1.6606 e-4 & -1.0028 e-4 & 2.6593 e-5 & -1.7107 e-4 & 1.7806 e-4 & -4.9549 e-5 \\
-2.2022 e-4 & -3.2553 e-5 & 7.7828 e-6 & 6.0134 e-6 & 1.3515 e-4 & -1.7911 e-4 \\
1.4089 e-4 & 3.3513 e-5 & -6.1045 e-6 & 8.2847 e-5 & -9.7390 e-5 & -2.5028 e-4 \\
-7.0949 e-5 & 4.6983 e-5 & -2.3091 e-5 & -2.5119 e-4 & -1.6219 e-4 & -5.3121 e-5
\end{array}\right] \text {. }
$$




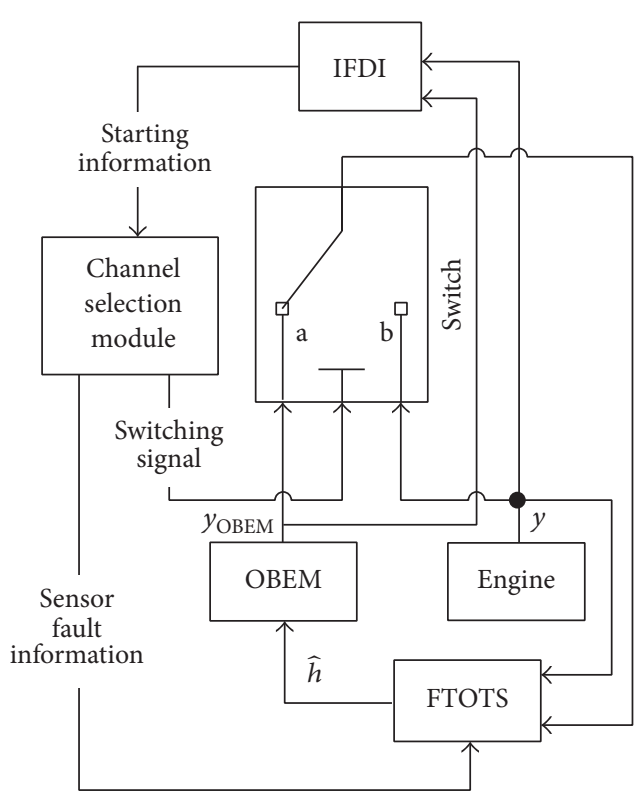

FIGURE 8: Switching channel between the FDI and the OTS.

2.3. Channel Switching Module. The outputs of the OBEM are used as baseline outputs of the HKF. To maintain the effectiveness of IFDI, the outputs of the OBEM should be tuned to minimize the mismatch between the OBEM and the actual engine caused by health degradation. If the process of OBEM tuning operates parallel to the HKF estimation, then the HKF estimation loses its accuracy, because during the working process the health parameters must remain at a reference level [2]. Without the fault information provided by the IFDI, the online tuning process is affected by the faulty signal. The switching module is designed to avoid the interference of the IFDI and the FTOTS.

There are two process channels in the structure: one is the IFDI estimation process, which is marked as "a," and the other is the FTOTS online tuning process, which is marked as "b." Both channels operate under the control of the switching module.

Firstly, the estimation channel is chosen and the estimation process of the IFDI is initiated. The IFDI is used to decide whether online tuning should be started, so channel "a" is originally chosen to make sure that the IFDI is able to complete the diagnostics process. After the estimation work of the IFDI, the channel selection module receives the corresponding information from the IFDI to initiate the channel switching process. If the IFDI provides the starting signal for the OBEM online tuning, then tuning channel " $b$ " will be chosen and the FTOTS will initiate online tuning. When the FTOTS completes the tuning process, the channel switching module switches to channel "a" to restart the estimation process. The switching structure is shown in Figure 8.

\section{Simulation Results}

The first simulation shows how the IFDI locates the faulty sensor based on the WSSR $_{\mathrm{HKF}}$ and makes an online tuning

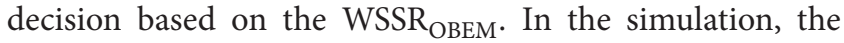
engine is working under static-state conditions, and at $t=1 \mathrm{~s}$ if the sensor of $\mathrm{OT}_{\mathrm{fan}}$ is faulty, then different HKFs provide a series of WSSRs. The different WSSR $\mathrm{HKF}_{\mathrm{HF}} \mathrm{s}$ and WSSR $\mathrm{OBEM}_{\mathrm{O}}$ of the faulty sensor are shown in Figure 9.

Figure 9(a) shows WSSR $_{\mathrm{HKF}}$ s of different sensors, and Figure 9 (b) shows how WSSR $_{\mathrm{OBEM}}$ of the faulty sensor $\lambda_{\mathrm{OT}_{\mathrm{fan}}}$ changes. The final values of different $\mathrm{WSSR}_{\mathrm{HKF}} \mathrm{s}$ are $\left[\begin{array}{llll}2.93 e-2 & 2.36 e-2 & 3.21 e-4 & 3.35 e-2\end{array}\right]$ corresponding to $\left[\begin{array}{llll}N_{H} & N_{L} & \mathrm{OT}_{\text {fan }} & \mathrm{OP}_{\text {fan }}\end{array}\right]$. The value of $\mathrm{WSSR}_{\mathrm{OBEM}}$ corresponding to the fault sensor of $\mathrm{OT}_{\mathrm{fan}}$ is $8.39 e-1$. In Figure 9(a), there are four lines representing WSSR $_{\mathrm{HKF}} \mathrm{S}$ and one line representing the threshold $\lambda_{\mathrm{OT}_{\mathrm{fan}}}$. WSSR $\mathrm{HKF}_{\mathrm{HK}}$ of the HKF corresponding to the faulty sensor $\mathrm{OT}_{\text {fan }}$ is much smaller than the others because the faulty signal does not affect the estimation results of the other HKFs. The WSSR $_{\mathrm{HKF}, \mathrm{OT}_{\text {fan }}}$ is lower than $\lambda_{\mathrm{OT}_{\text {fan }} \text {, }}$ and the other $\mathrm{WSSR}_{\mathrm{HKF}} \mathrm{S}$ are higher than it; thus, the faulty sensor is located. In Figure 9(b), $\eta_{\mathrm{OT}_{\mathrm{fan}}}$ is the threshold. The value of WSSR $_{\mathrm{OBEM}, \mathrm{OT}}$ fan is higher than $\eta_{\mathrm{OT}_{\mathrm{fan}}}$, which means the mismatch between the OBEM and the actual engine is unacceptable. The diagnostics logic referenced in this paper is proved by the simulation.

The thresholds $\lambda_{\mathrm{OT}_{\mathrm{fan}}}$ and $\eta_{\mathrm{OT}}$ ara are selected based on the standard deviation of the sensor. In this paper, the thresholds are set as the squared sum of the standard deviations to avoid a false diagnostics result. According to the standard deviations of different sensors in the literature [10], the thresholds can be computed. As the magnitudes of the different thresholds are of the same order, the other thresholds are not shown.

The second simulation shows the effectiveness of the OTS. In the simulation, the engine is working under static-state conditions. At $t=1 \mathrm{~s}$, the efficiency of the fan and HPC decreases by $5 \%$ simultaneously, and the other health parameters remain unchanged. The remaining input parameters and health parameters remain at their origin values, and the effectiveness deterioration of fan and HPC causes variation in the actual engine measured outputs such as $N_{H}$ and $N_{L}$. The estimated health parameters and estimated measured outputs are shown in Figure 10.

Figures 10(a) and 10(b) show the health parameters estimated by the HKF and the OTS, and Figures 10(c) and $10(\mathrm{~d})$ show the estimated measured outputs of the HKF and the OTS. During health degradation, the value of $N_{H}$ is reduced from $7963 \mathrm{r} / \mathrm{min}$ to $7285 \mathrm{r} / \mathrm{min}$, and the value of $N_{L}$ is reduced from $4341 \mathrm{r} / \mathrm{min}$ to $4052 \mathrm{r} / \mathrm{min}$. The estimation results of $\left[N_{H} N_{L}\right]$ of the OTS are [7285 r/min $4052 \mathrm{r} / \mathrm{min}]$, and the estimation results of $\left[\begin{array}{ll}N_{H} & N_{L}\end{array}\right]$ of the HKF are [7263 r/min $\left.4034 \mathrm{r} / \mathrm{min}\right]$.

According to Figures 10(a) and 10(b), the OTS and the HKF are both able to estimate the variations of component deterioration in the situation of multiple component deterioration. However, the estimation accuracy of the HKF is lower than that of the OTS. In Figures 10(c) and 10(d), the estimated outputs of the OTS are more accurate.

In the HKF structure, the estimated measured outputs are computed by a Kalman filter, so the estimation accuracy 


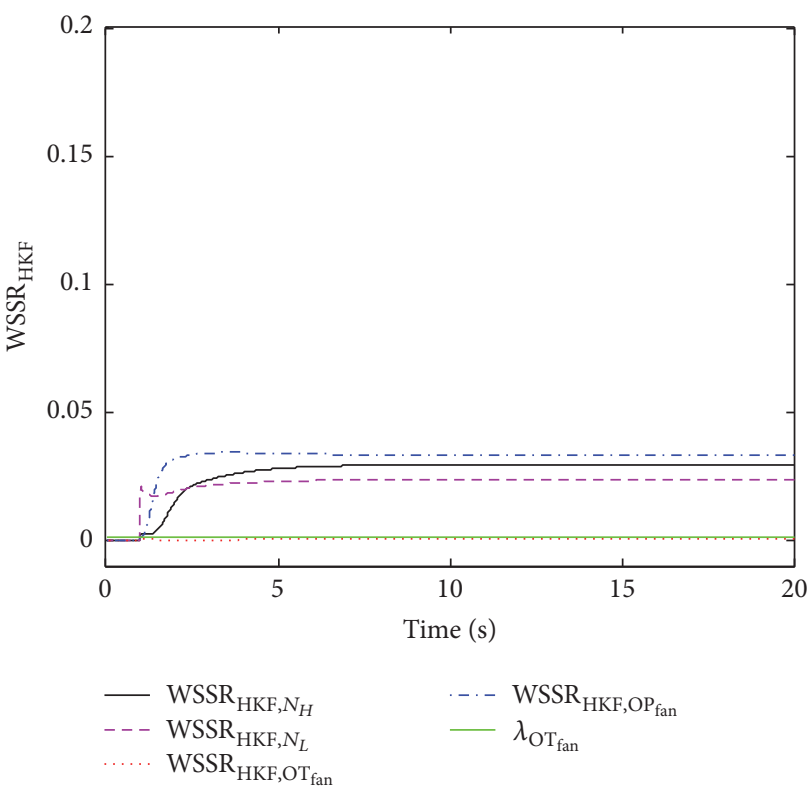

(a) $\mathrm{WSSR}_{\mathrm{HKF}} \mathrm{s}$ of different HKFs

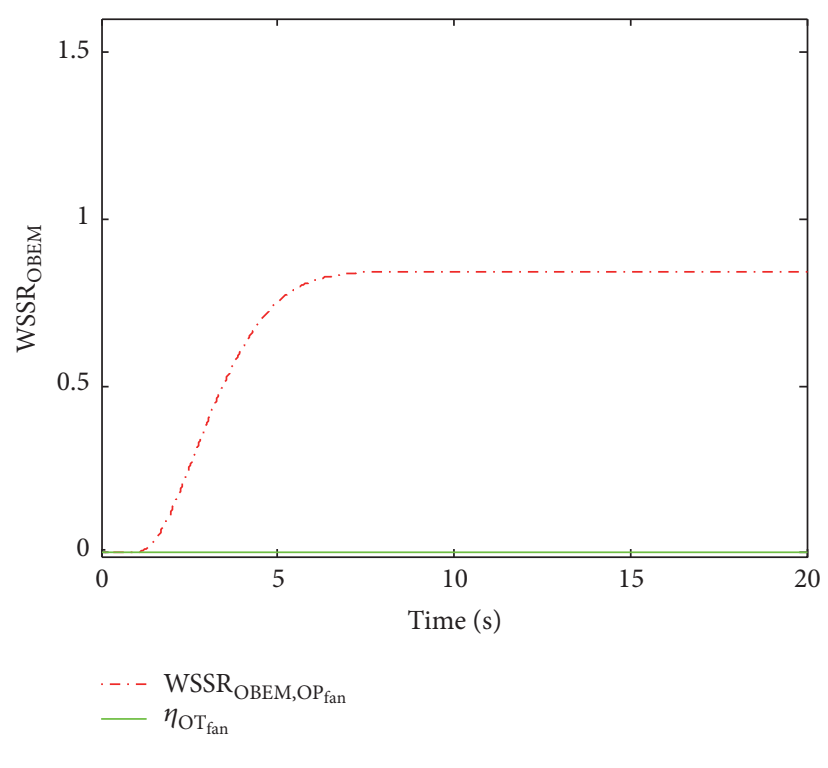

(b) $\mathrm{WSSR}_{\mathrm{OBEM}}$ s of faulty sensor $\mathrm{OT}_{\text {fan }}$

FIGURE 9: WSSRs of the IFDI.

is affected by the linearization accuracy state-space formulation of the Kalman filter. While in the OTS the estimated measured outputs are computed by the nonlinear OBEM, the estimation accuracy of the OTS can be guaranteed because of the high degree of matching between the OBEM and the actual engine.

The third simulation shows the effectiveness of the FTOTS and the influence of a faulty signal during the tuning process. In the simulation, the engine is working under staticstate conditions. At $t=1 \mathrm{~s}$, the effectiveness of the fan and the HPC decreases by $5 \%$, the other health parameters remain unchanged, and the sensor of $\mathrm{OT}_{\mathrm{fan}}$ is faulty. The value of the signal from the faulty sensor is $200 \mathrm{~K}$ higher than the actual value. The estimated health parameters and measured outputs between the FTOTS with fault information and that without fault information are shown in Figure 11.

Figures 11(a) and 11(b) show the estimated health parameters of the FTOTS, Figures 11(c), 11(d) and 11(e) show the estimated outputs of the FTOTS, and Figure 11(f) shows the difference between $\mathrm{OT}_{\mathrm{fan}}$ from the faulty sensor and the actual output. During the health degradation, the value of $N_{H}$ is reduced from $7963 \mathrm{r} / \mathrm{min}$ to $7285 \mathrm{r} / \mathrm{min}$, the value of $N_{L}$ is reduced from $4341 \mathrm{r} / \mathrm{min}$ to $4052 \mathrm{r} / \mathrm{min}$, and the actual value of $\mathrm{OT}_{\text {fan }}$ is reduced from $309.8 \mathrm{~K}$ to $308.7 \mathrm{~K}$. If the correct fault information is received by the FTOTS, the estimation results of $\left[\begin{array}{llll}N_{H} & N_{L} & \mathrm{OT}_{\text {fan }}\end{array}\right]$ of the OTS are [7285 r/min $4052 \mathrm{r} / \mathrm{min} 308.7 \mathrm{~K}$ ]; otherwise, the estimation results of $\left[\begin{array}{llll}N_{H} & N_{L} & \mathrm{OT}_{\mathrm{fan}}\end{array}\right]$ of the OTS are [7468 r/min $3917 \mathrm{r} / \mathrm{min} 312.8 \mathrm{~K}]$.

When the FTOTS receives the correct fault information, it is able to remove the faulty signal and complete the tuning process with the correct estimation results, while the faulty signal causes incorrect tuning results of the FTOTS. The FTOTS is able to minimize the mismatch between the OBEM and the actual engine based on the correct fault information when the sensor fault and health degradation coexist.

In the final simulation, the simulation results prove the effectiveness of the fault-tolerant OBEM tuning structure. In the simulation, the engine is working under static-state conditions. At $t=1 \mathrm{~s}$, the effectiveness of the fan and HPC decreases by $5 \%$, and the other health parameters remain unchanged. The sensor of $\mathrm{OT}_{\mathrm{fan}}$ is faulty at the same time, and the value of the signal from the faulty sensor is $200 \mathrm{~K}$ higher than the actual value. The corresponding simulation results are shown in Figure 12.

Figure 12(a) shows the sensor fault location signal of the IFDI, Figure 12(b) shows WSSR ${ }_{\mathrm{HKF}} \mathrm{s}$ of different HKFs in the IFDI and the threshold $\lambda_{\mathrm{OT}_{\mathrm{fan}}}$, Figure 12(c) shows the channel switching process of the system, Figure 12(d) shows WSSR $_{\text {OBEM }}$ of the faulty sensor, and Figure $12(\mathrm{e})$ shows the variation rate of health parameters. Figures 12(f), 12(g), and 12(h) show the computed measured outputs of the OBEM, and Figures 12(i) and 12(j) show the health parameters estimated by the FTOTS.

In Figures 12(a) and 12(b), at $1.8 \mathrm{~s}$, the fault signal of the IFDI assumes a value of three to locate the faulty sensor according to the variation in $\mathrm{WSSR}_{\mathrm{HKF}} \mathrm{s}$ and threshold $\lambda_{\mathrm{OT}_{\mathrm{fan}}}$ during the estimation process and remains at a value of three during tuning process. In Figures 12(c), 12(d), and 12(e), at $1.8 \mathrm{~s}$, the channel switching signal assumes a value of -1 when $\mathrm{WSSR}_{\mathrm{OBEM} \mathrm{OT}_{\text {fan }}}$ is higher than the threshold $\eta_{\mathrm{OT}_{\mathrm{fan}}}$, and the tuning process is initiated. When WSSR $\mathrm{OBEM}_{\text {, OT }}$ is lower than the threshold $\eta_{\mathrm{OT}_{\mathrm{fan}}}$ and the variation rate of the health parameter approaches zero, the switching signal turns to a value of one at $9.3 \mathrm{~s}$ to restart the estimation process. In Figures 12(f), 12(g), and 12(h), during the original estimation process, the outputs of the OBEM remain at their original values to provide baseline outputs for the IFDI. When the 


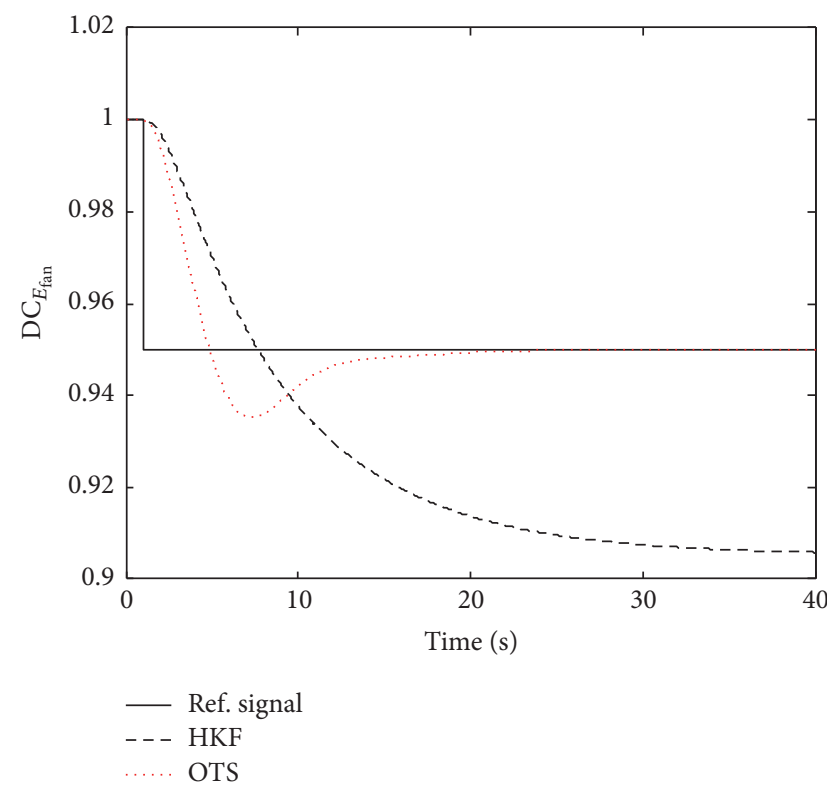

(a) DC_ $E_{\text {fan }}$ comparison between two systems

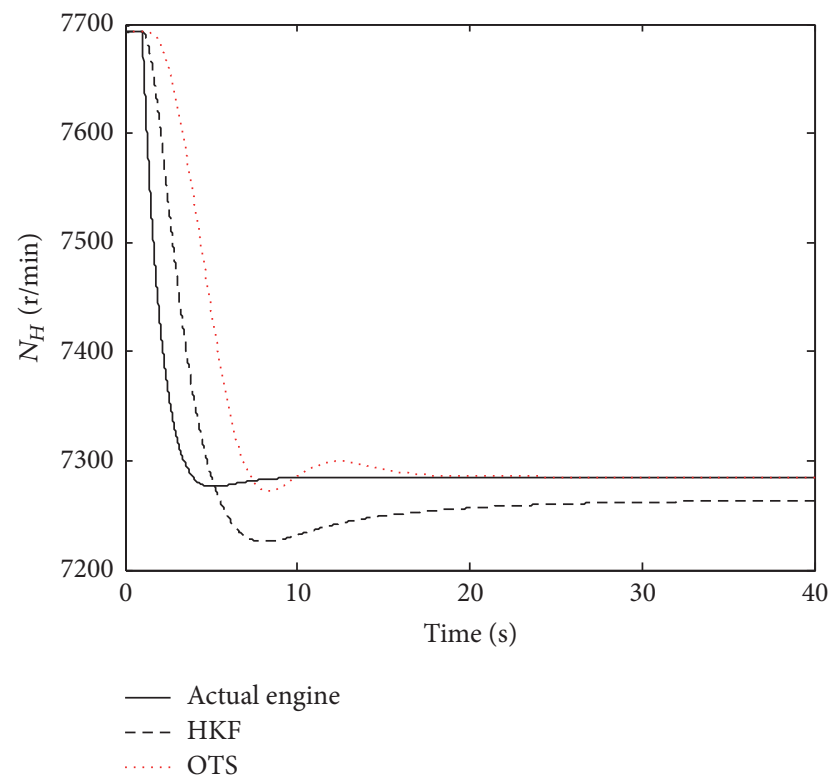

(c) $N_{H}$ comparison between two systems

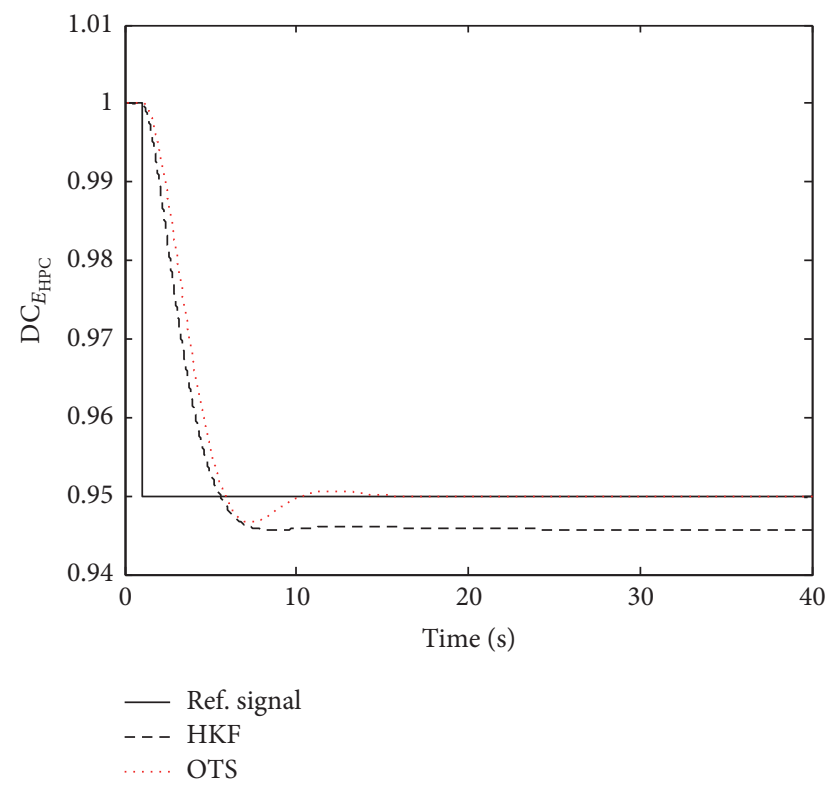

(b) DC_E $E_{\mathrm{HPC}}$ comparison between two systems

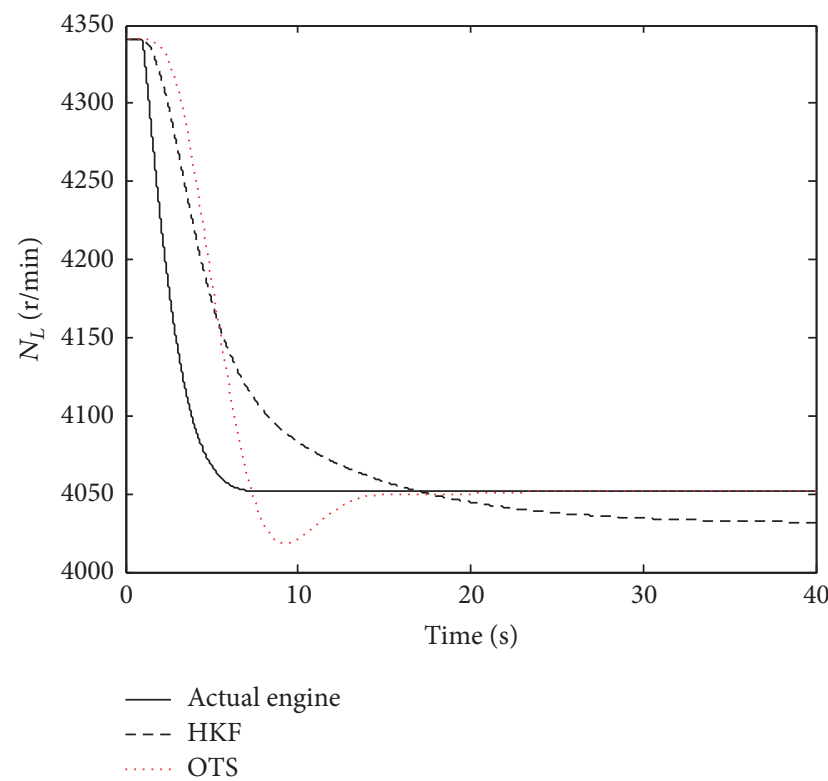

(d) $N_{L}$ comparison between two systems

FIGURE 10: Comparisons of estimated results between the HKF and OTS.

tuning process is started, the outputs of the OBEM will track the outputs of the actual engine under the control of the FTOTS. During the tuning process, the deviation of the measured outputs between the OBEM and the actual engine is minimized by the FTOTS, and the faulty signal does not affect the tuning results. In Figures 12(i) and 12(j), the estimated health parameters of the FTOTS are used to show the health degradation of the engine and the FTOTS is able to update the OBEM online, based on the estimated health information. According to the simulation results, the effectiveness of the fault-tolerant OBEM tuning structure is proven. This system is able to successfully locate the faulty sensor and make the online tuning decision during the estimation process and complete the tuning process without the influence of a faulty sensor.

\section{Conclusions}

A fault-tolerant online OBEM tuning structure is developed to minimize the mismatch caused by health degradation and to protect the OBEM tuning process from the influence of faulty signals when sensor fault and health degradation coexist. Moreover, the estimation accuracy of the online tuning structure is improved. In this structure, the IFDI is designed to locate the faulty sensor and make tuning operation decision, the FTOTS is designed to complete the 


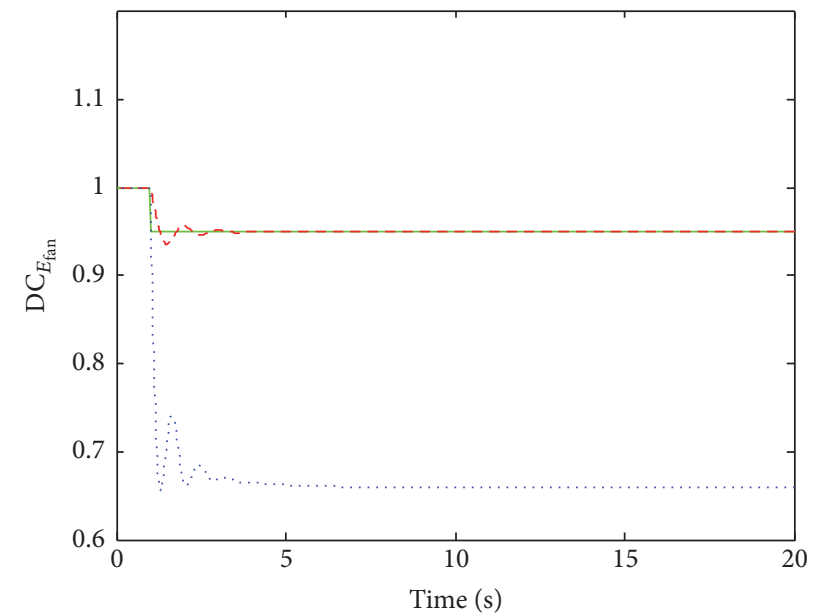

_ Ref. signal

- . - With fault information

(a) $\mathrm{DC}_{E_{\mathrm{fan}}}$ of FTOTS

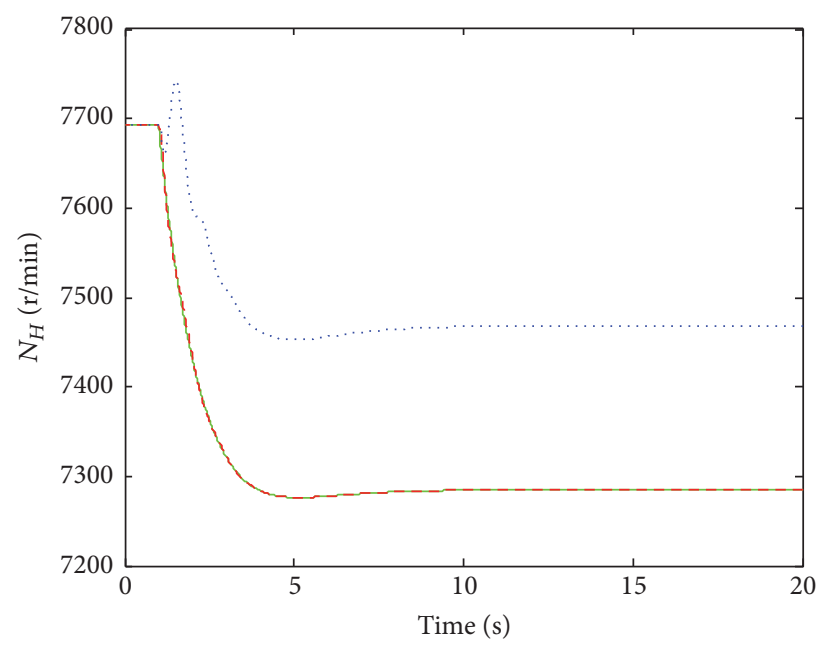

Actual engine

- - - With fault information

(c) $N_{H}$ of FTOTS

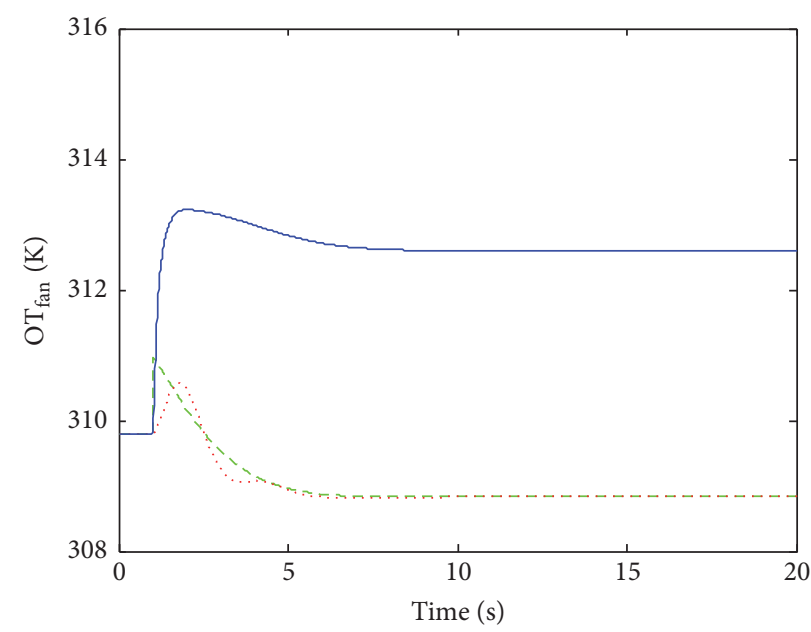

- - Output of actual engine With fault information

- Without fault information

(e) $\mathrm{OT}_{\text {fan }}$ estimated by FTOTS

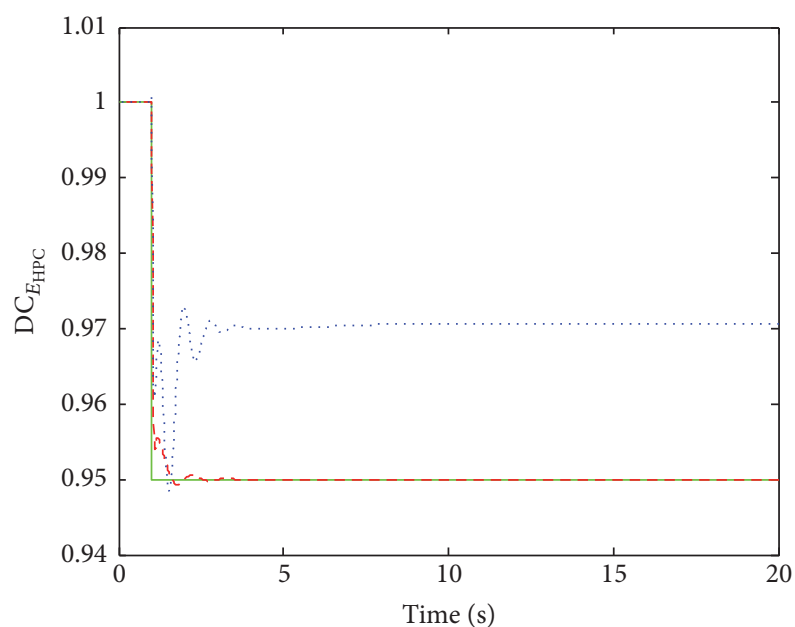
$\begin{array}{ll}\text { _ Ref. signal } & \text {...... Without fault information } \\ \text { _ - - With fault information } & \end{array}$

(b) $\mathrm{DC}_{E_{\mathrm{HPC}}}$ of FTOTS

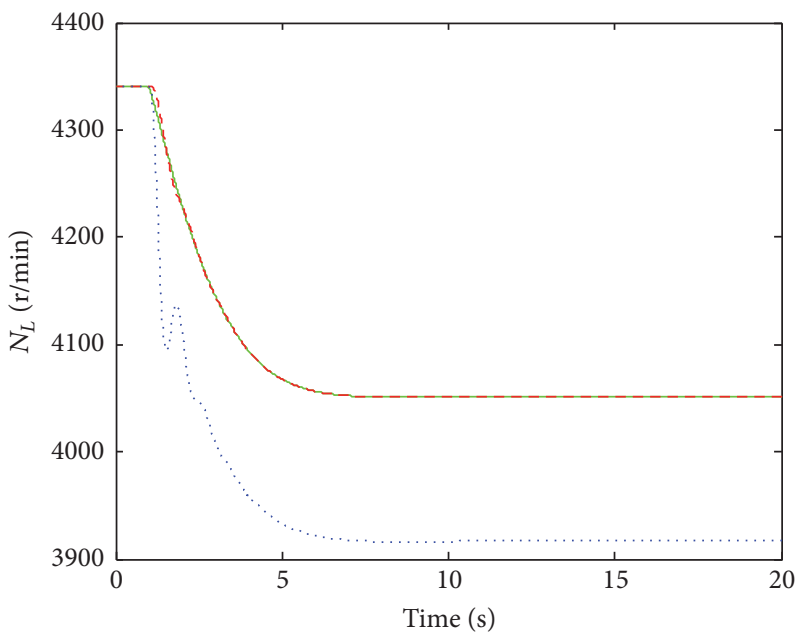

- - With fault information

(d) $N_{L}$ of FTOTS

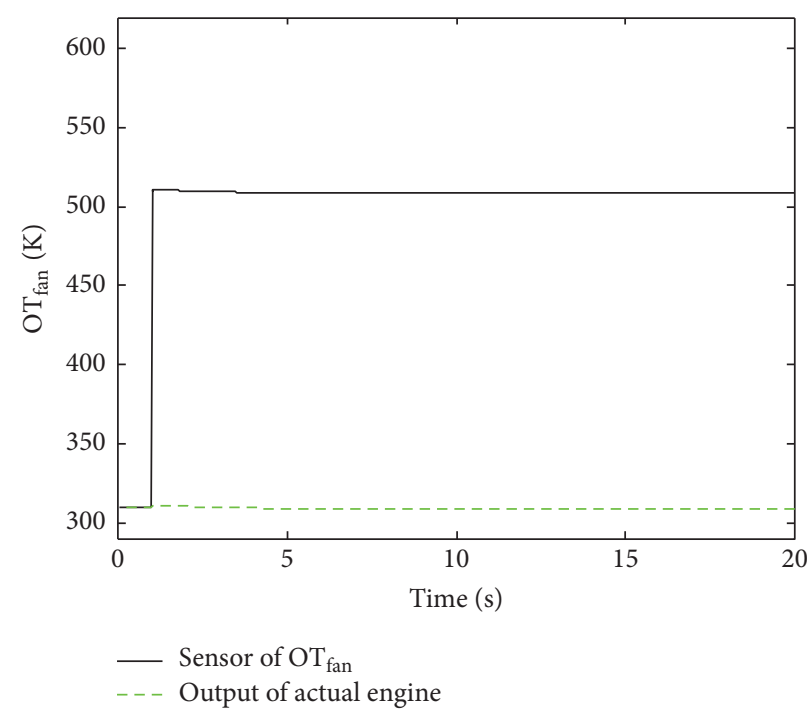

(f) $\mathrm{OT}_{\text {fan }}$ from faulty sensor and actual output

FIgURE 11: Estimated results of the FTOTS. 


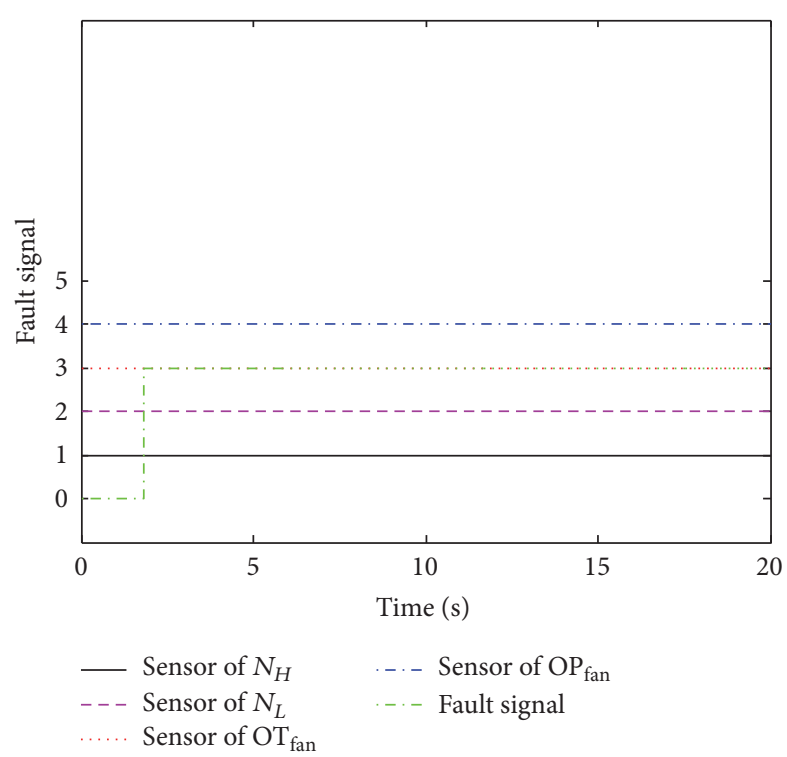

(a) Fault signal of IFDI

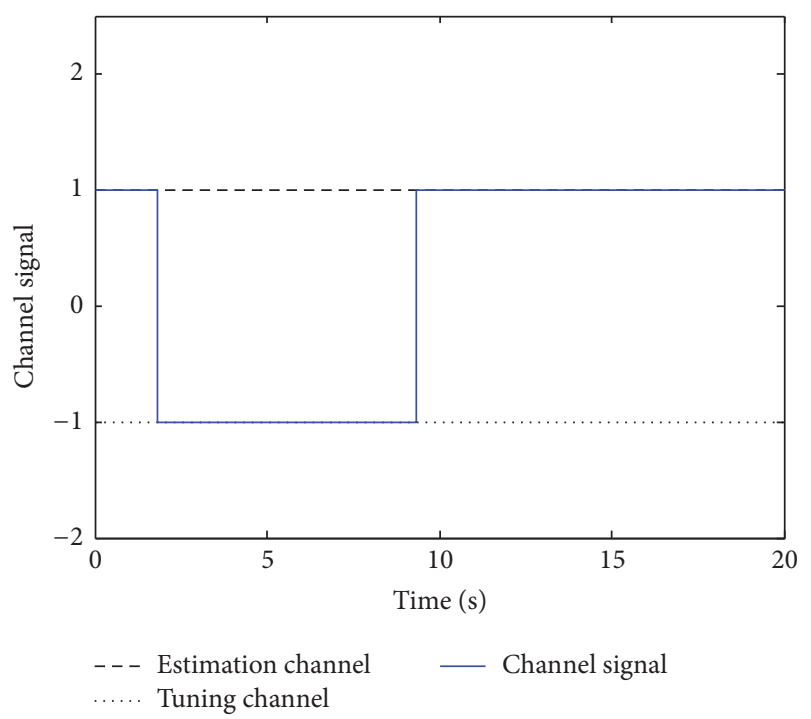

(c) Channel switching signal

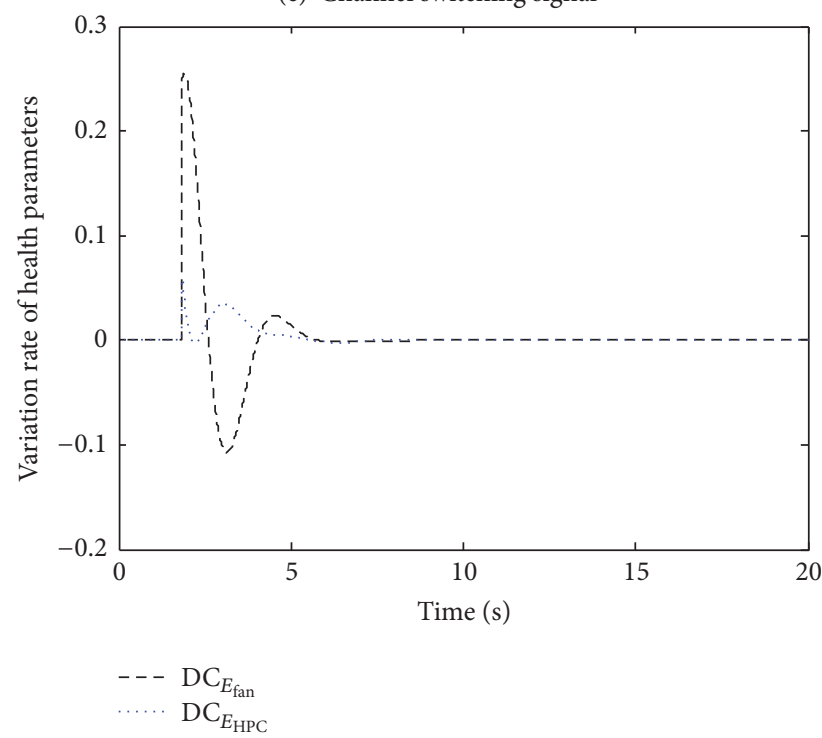

(e) Variation rate of health parameters

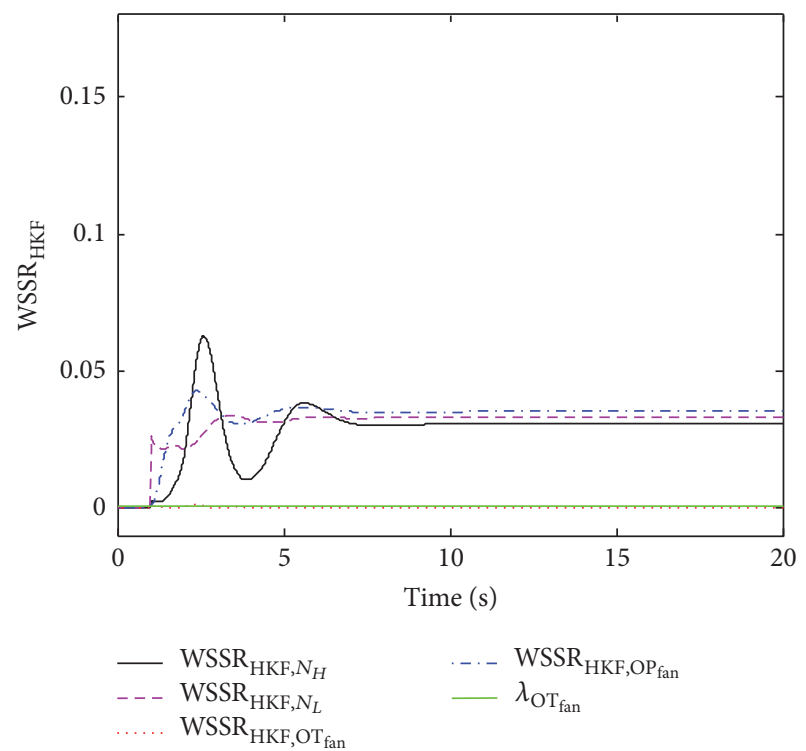

(b) WSSR $_{\mathrm{HKF}} \mathrm{s}$ of IFDI

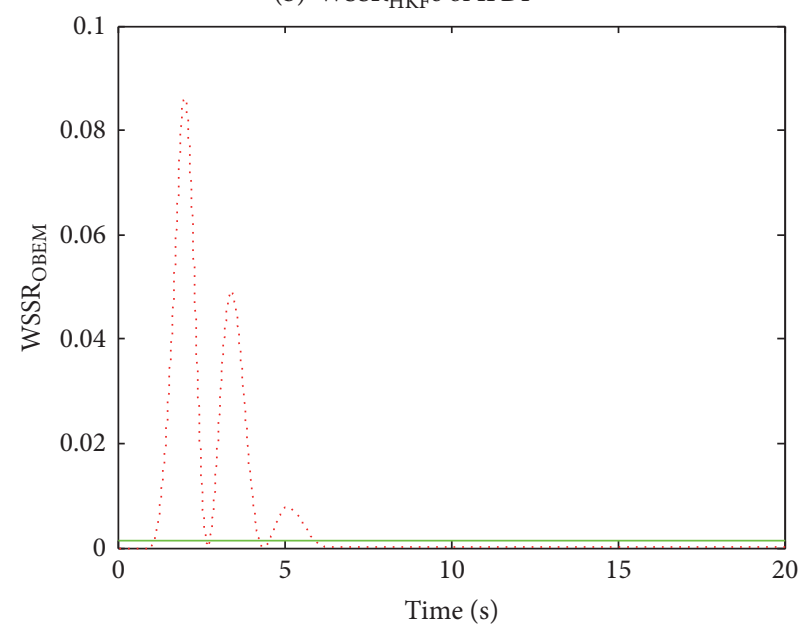

WSSR $_{\mathrm{OBEM}}$ of $\mathrm{OT}_{\mathrm{fan}}$

$\eta_{\mathrm{OT}_{\mathrm{fan}}}$

(d) $\mathrm{WSSR}_{\mathrm{OBEM}}$ corresponding to $\mathrm{OT}_{\mathrm{fan}}$

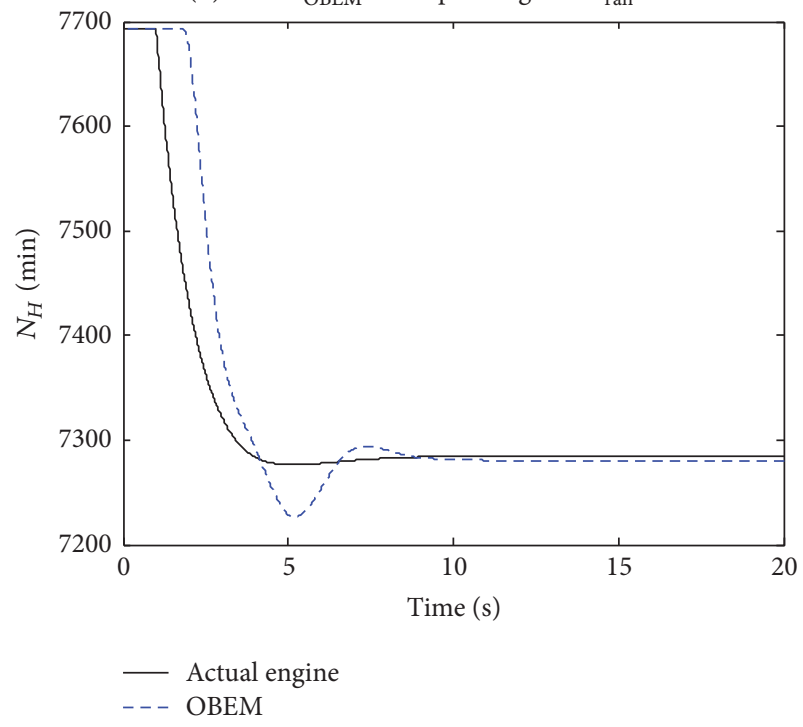

(f) $N_{H}$ of OBEM

Figure 12: Continued. 


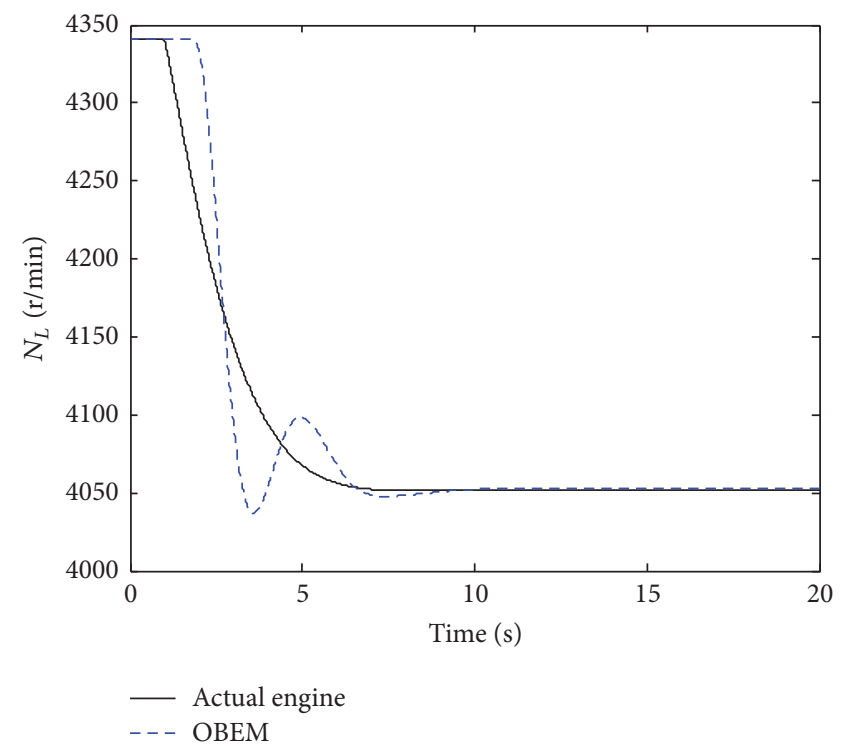

(g) $N_{L}$ of OBEM

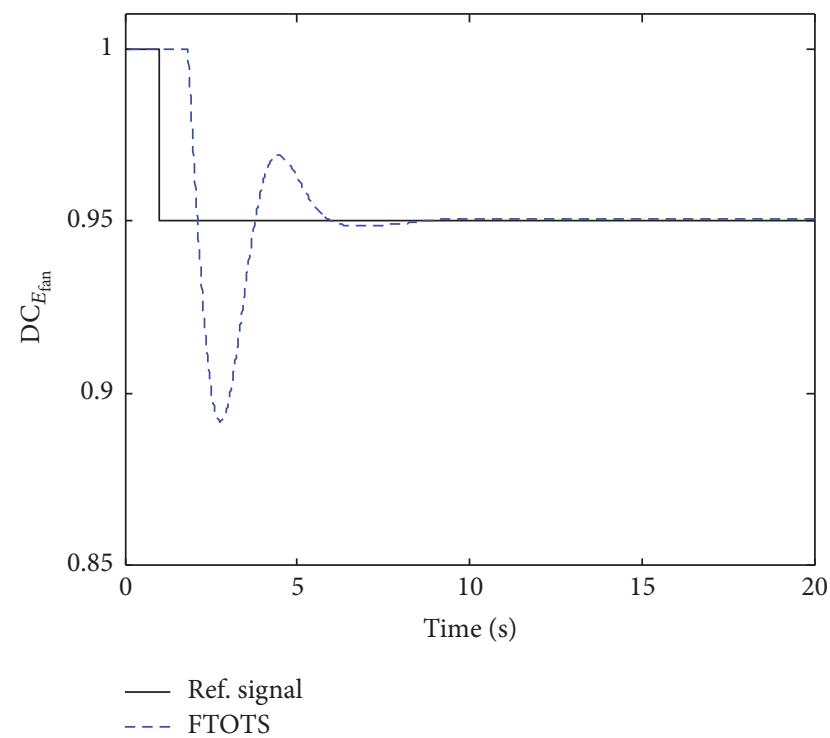

(i) $\mathrm{DC}_{E_{\text {fan }}}$ estimated by FTOTS

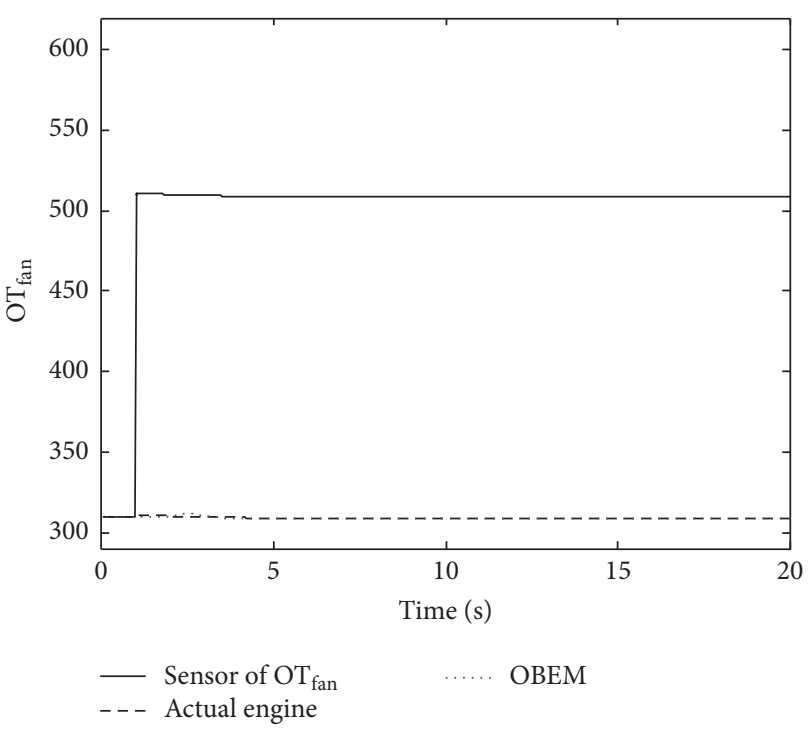

(h) $\mathrm{OT}_{\text {fan }}$ of OBEM

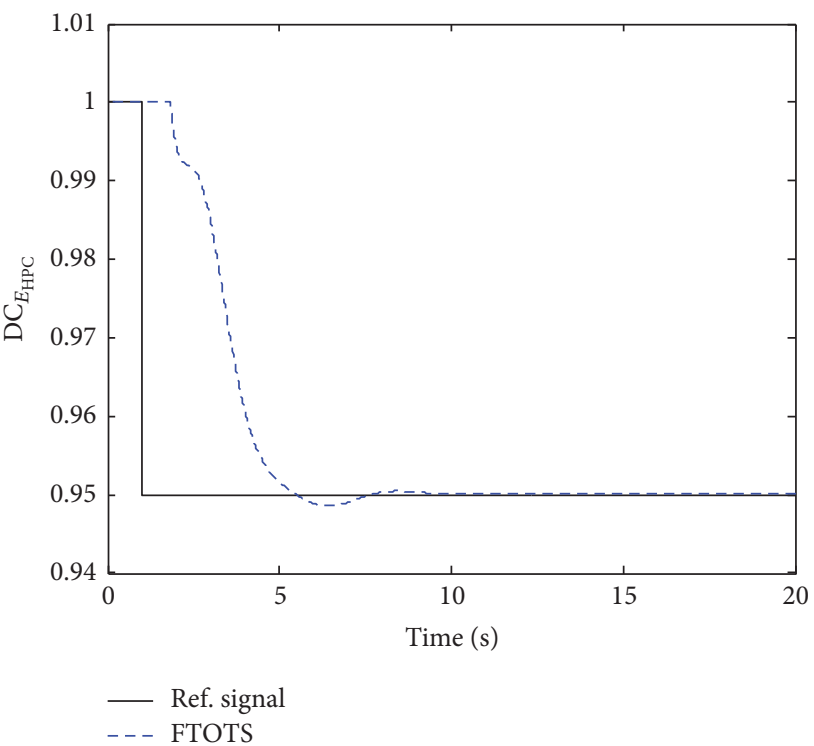

(j) $\mathrm{DC}_{E_{\mathrm{HPC}}}$ estimated by FTOTS

FIGURE 12: Simulation results of switching process of system.

online tuning process with the help of the fault information from the IFDI, and a channel switching module is designed to separate the estimation process and tuning process to avoid interference between the IFDI and the FTOTS. The effectiveness of the fault-tolerant tuning structure is proven in this paper by a series of simulations, and the simulation results show that fault-tolerant OBEM tuning structure is able to separate health degradation and sensor fault, in addition to being able to complete the online tuning process, regardless of the presence of a faulty sensor. In future research, the diagnostics system used to deal with the coexistence of health degradation and actuator fault or the coexistence of actuator fault and sensor fault will be developed.

\section{Notations}

Symbol

$h$ : Performance degradation factor

$u$ : Input parameter

$v$ : White measurement noise

$w$ : White process noise

$x$ : State parameter

$y$ : Output parameter

$z$ : Environmental parameter

DC: Degradation coefficient

E: Effectiveness 
EGT: Engine exhaust temperature (K)

EGP: Engine exhaust pressure $(\mathrm{Pa})$

$F$ : $\quad$ Flow capacity

FS: Fault signal

QM: $\quad$ State deviations weighting matrix

RM: Control deviations weighting matrix

IM: Identity matrix

ISF: Input selection function

N: $\quad$ Rotor speed

OT: $\quad$ Outlet temperature $(\mathrm{K})$

OP: $\quad$ Outlet pressure $(\mathrm{Pa})$

Q: $\quad$ State weighting matrix

$R$ : $\quad$ Output weighting matrix

$W$ : Mass flow

WSSR: Weighted sum of squared residuals

$\delta$ : $\quad$ Scheduling parameter.

\section{Subscripts}

kal: Kalman filter

ref: Reference

lq: Linear quadratic

ss: $\quad$ Steady state

$H$ : High pressure

HPC: High pressure compressor

HPT: High pressure turbine

L: $\quad$ Low pressure

LPC: Low pressure compressor

LPT: Low pressure turbine

0 : $\quad$ Initial value.

\section{Competing Interests}

The authors declare that they have no competing interests.

\section{References}

[1] J. B. Armstrong and D. L. Simon, "Implementation of an integrated on-board aircraft engine diagnostic architecture," in Proceedings of the 47th AIAA/ASME/SAE/ASEE Joint Propulsion Conference \& Exhibit, AIAA-2011-5859, San Diego, Calif, USA, August 2011.

[2] T. Kobayashi and D. L. Simon, "Integration of on-line and offline diagnostic algorithms for aircraft engine health management," Journal of Engineering for Gas Turbines and Power, vol. 129, no. 4, pp. 986-993, 2007.

[3] J. A. Turso and J. S. Litt, "A foreign object damage event detector data fusion system for turbofan engines," Journal of Aerospace Computing, Information and Communication, vol. 2, no. 7, pp. 291-308, 2005.

[4] T. J. Grindle and F. W. Burcham Jr., "Engine damage to a NASA DC-8-72 airplane from a high-altitude encounter with a diffuse volcanic ash cloud," NASA/TM-2003-212030, 2003.

[5] C. Hajiyev and F. Caliskan, "Sensor/actuator fault diagnosis based on statistical analysis of innovation sequence and Robust Kalman Filtering," Aerospace Science and Technology, vol. 4, no. 6, pp. 415-422, 2000.

[6] F. Caliskan and C. M. Hajiyev, "Aircraft sensor fault diagnosis based on Kalman filter innovation sequence," in Proceedings of the 37th IEEE Conference on Decision and Control, vol. 2, pp. 1313-1314, Tampa, Fla, USA, December 1998.

[7] T. Kobayashi and D. L. Simon, "Evaluation of an enhanced bank of Kalman filters for in-flight aircraft engine sensor fault diagnostics," Journal of Engineering for Gas Turbines and Power, vol. 127, no. 3, pp. 497-504, 2005.

[8] T. Kobayashi and D. L. Simon, "Application of a bank of Kalman filters for aircraft engine fault diagnostics," in Proceedings of the ASME Turbo Expo 2003, Collocated with the 2003 International Joint Power Generation Conference, vol. 1, pp. 461-470, American Society of Mechanical Engineers, Atlanta, Ga, USA, June 2003.

[9] W. Xue, Y.-Q. Guo, and X.-D. Zhang, "A bank of Kalman filters and a Robust Kalman filter applied in fault diagnosis of aircraft engine sensor/actuator," in Proceedings of the 2nd International Conference on Innovative Computing, Information and Control (ICICIC '07), Kumamoto, Japan, September 2007.

[10] K. Salahshoor, M. Mosallaei, and M. Bayat, "Centralized and decentralized process and sensor fault monitoring using data fusion based on adaptive extended Kalman filter algorithm," Measurement, vol. 41, no. 10, pp. 1059-1076, 2008.

[11] M. Joerger and B. Pervan, "Kalman filter-based integrity monitoring against sensor faults," Journal of Guidance, Control, and Dynamics, vol. 36, no. 2, pp. 349-361, 2013.

[12] B. Pourbabaee, N. Meskin, and K. Khorasani, "Robust sensor fault detection and isolation of gas turbine engines subjected to time-varying parameter uncertainties," Mechanical Systems \& Signal Processing, vol. 76-77, pp. 136-156, 2016.

[13] S. Garg, "Controls and health management technologies for intelligent aerospace propulsion systems," in Proceedings of the 42nd AIAA Aerospace Sciences Meeting and Exhibit, AIAA2004-949, pp. 11854-11876, Reno, Nev, USA, January 2004.

[14] J. S. Litt, D. L. Simon, S. Garg et al., "A survey of intelligent control and health management technologies for aircraft propulsion systems," Journal of Aerospace Computing, Information and Communication, vol. 1, no. 12, pp. 543-563, 2004.

[15] A. Behbahani, S. Adibhatla, and C. Rauche, "Integrated modelbased controls and PHM for improving turbine engine performance, reliability, and cost," in Proceedings of the 45th AIAA/ASME/SAE/ASEE Joint Propulsion Conference \& Exhibit, AIAA 2009-5534, Denver, Colo, USA, August 2009.

[16] T. Kobayashi and D. L. Simon, "Hybrid Kalman filter: a new approach for aircraft engine in-flight diagnostics," ARL-TR 4001, 2006.

[17] T. Kobayashi and D. L. Simon, "Hybrid Kalman filter approach for aircraft engine in-flight diagnostics: sensor fault detection case," Journal of Engineering for Gas Turbines and Power, vol. 129, no. 3, pp. 746-754, 2006.

[18] S. Garg, "Propulsion controls and diagnostics research at NASA Glenn," Tech. Rep. AIAA-2007-5713, 2007.

[19] D. L. Simon and S. Garg, "A systematic approach for modelbased aircraft engine performance estimation," in Proceedings of the AIAA Infotech@Aerospace Conference, Infotech@Aerospace Conferences, AIAA-2009-1872, pp. 2009-1872, Seattle, Wash, USA, April 2009.

[20] B. Pourbabaee, N. Meskin, and K. Khorasani, "Multiple-model based sensor fault diagnosis using hybrid Kalman filter approach for nonlinear gas turbine engines," in Proceedings of the 1st American Control Conference (ACC '13), pp. 4717-4723, IEEE, Washington, DC, USA, June 2013. 
[21] B. Pourbabaee, N. Meskin, and K. Khorasani, "Sensor fault detection, isolation, and identification using multiple-modelbased hybrid Kalman filter for gas turbine engines," IEEE Transactions on Control Systems Technology, vol. 24, no. 4, pp. 1184-1200, 2015.

[22] J. B. Armstrong and D. L. Simon, "Constructing an efficient selftuning aircraft engine model for control and health management applications," in Proceedings of the 2012 Annual Conference of the Prognostics and Health Management Society (PHM '12), NASA/TM-2012-217806, pp. 134-146, Minneapolis, Minn, USA, September 2012.

[23] D. L. Simon and J. B. Armstrong, "An integrated approach for aircraft engine performance estimation and fault diagnostics," Journal of Engineering for Gas Turbines and Power, vol. 135, no. 7, Article ID 071203, 2013.

[24] A. W. Rinehart and D. L. Simon, "An integrated architecture for aircraft engine performance monitoring and fault diagnostics: engine test results," in Proceedings of the 50th AIAA/ASME/ SAE/ASEE Joint Propulsion Conference, Propulsion and Energy Forum, Cleveland, Ohio, USA, July 2014.

[25] A. Volponi, "Enhanced self tuning on-board real-time model (eSTORM) for aircraft engine performance health tracking," Tech. Rep. FR-26751, 2008.

[26] A. Volponi, T. Brotherton, and R. Luppold, "Empirical tuning of an on-board gas turbine engine model for real-time module performance estimation," Journal of Engineering for Gas Turbines and Power, vol. 130, no. 2, Article ID 021604, pp. 669-678, 2008.

[27] L. C. Jaw and J. D. Mattingly, Aircraft Engine Controls-Design, System Analysis, and Health Monitoring, American Institute of Aeronautics and Astronautics, Reston, Va, USA, 2009.

[28] D. T. Pham, J. Verron, and M. C. Roubaud, "A singular evolutive extended Kalman filter for data assimilation in oceanography," Journal of Marine Systems, vol. 16, no. 3-4, pp. 323-340, 1998.

[29] G. A. Dukeman, "Profile-following entry guidance using linear quadratic regulator theory," in Proceedings of the AIAA Guidance, Navigation, and Control Conference and Exhibit, AIAA2002-4457, Monterey, Calif, USA, August 2002.

[30] A. Bemporad, M. Morari, V. Dua, and E. N. Pistikopoulos, "The explicit linear quadratic regulator for constrained systems," Automatica, vol. 38, no. 1, pp. 3-20, 2002.

[31] L. Reberga, D. Henrion, J. Bernussou, and F. Vary, "LPV modeling of a turbofan engine," in Proceedings of the 16th IFAC World Congress, Prague, Czech Republic, July 2005.

[32] R. Tóth, "Modeling and identification of linear parametervarying systems," Lecture Notes in Control and Information Sciences, vol. 403, pp. 1-339, 2010. 


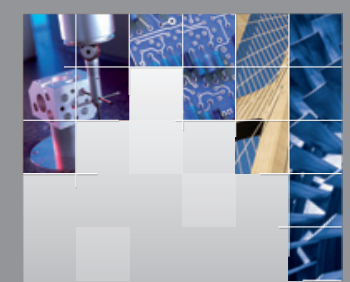

\section{Enfincering}
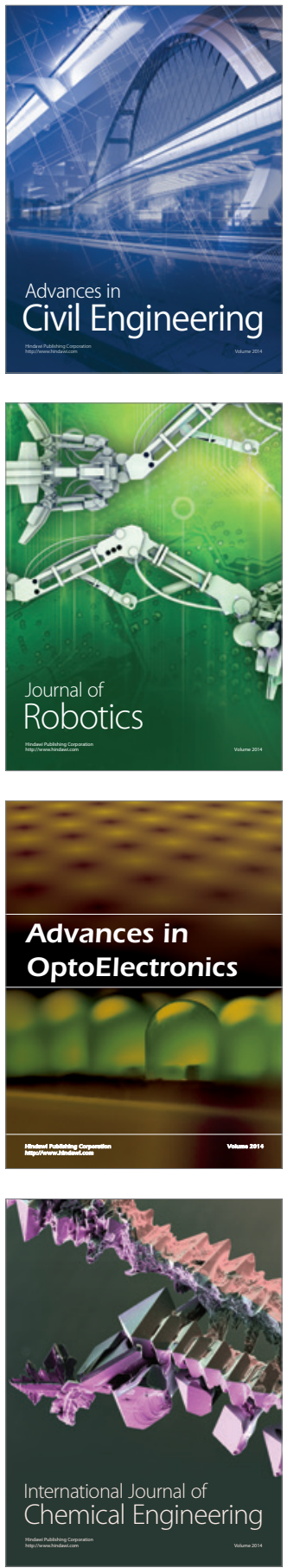

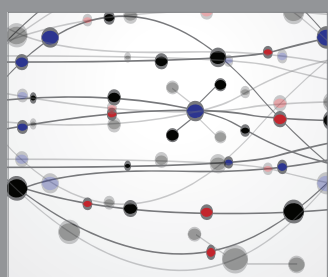

The Scientific World Journal

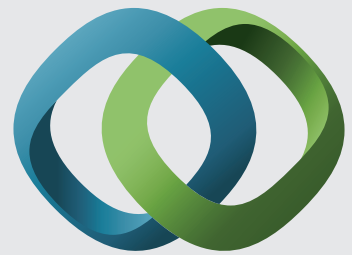

\section{Hindawi}

Submit your manuscripts at

http://www.hindawi.com
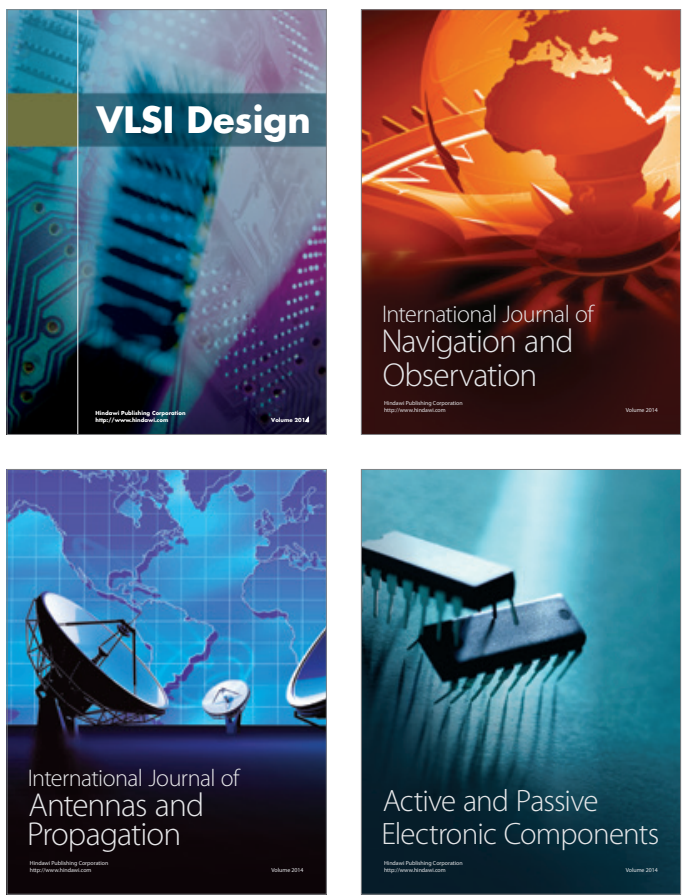
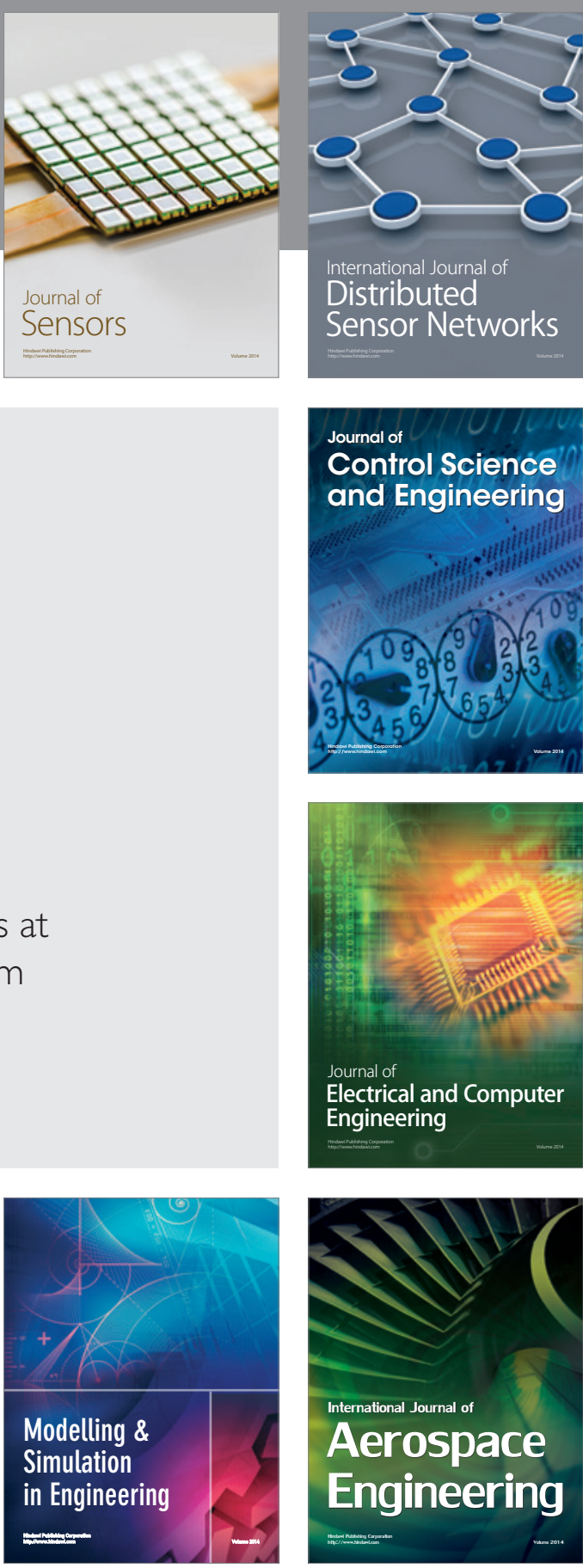

International Journal of

Distributed

Sensor Networks

Journal of

Control Science

and Engineering
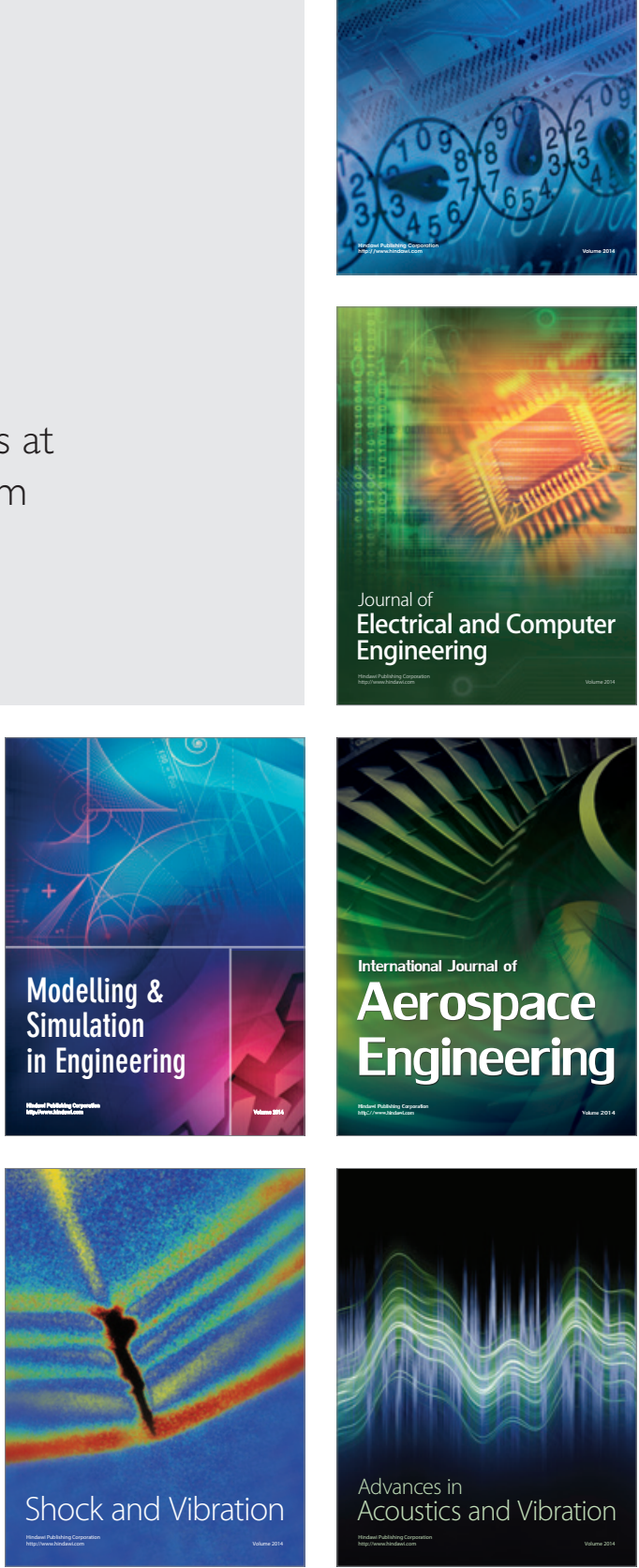